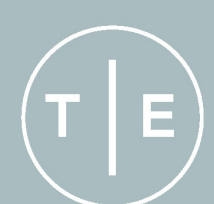

Trabajos de Egiptología

"Those Who Mourn for Re": Mourning and Regeneration in the Book of the Twelve Caverns

Daniel Miguel MÉNDEZ RODRíGUEZ

The Courtyard of TT 209 (Areas C1 and C2). Seasons 2012 to 2014

Miguel Ángel MOLINERO POLO, Cristo Manuel HERNÁNDEZ GÓMEZ.

Algunas reflexiones sobre Uluburun y el intercambio comercial y cultural en el Mediterráneo Oriental

$$
\text { Antonio PÉREZ LARGACHA }
$$

The Framework of the Meeting

Narrative Uses of Stelae in Egyptian Literary Texts José Ramón PÉREZ-ACCINO

Introducción a la investigación arqueológica para estudiantes a través de reconstrucciones virtuales

Sofía PÉREZ-RUIZ, Ainara ACEBO, Pilar RODRÍGUEZ MARíN...

Lucernas decoradas con la imagen de una rana del yacimiento de Oxirrinco, El-Bahnasa, Egipto Esther PONS MELLADO

\section{Trabajos de Egiptología}

\section{Papers on Ancient Egypt}

Estudio preliminar de la cerámica procedente de las excavaciones en la TT 209, Luxor, Egipto

$$
\text { Zulema BARAHONA MENDIETA }
$$

La ocupación macedónica y la Dinastía Lágida. Impacto político, económico y social Francisco BOSCH PUCHE

Reflexiones sobre Meretseguer en la estela EA272 del British Museum

Elisa CASTEL RONDA

Ramesses III as Guarantor of Maat: the Iconographic Evidence at Medinet Habu

$$
\text { Salvador COSTA, Teresa MAGADÁN }
$$

Iconographic Rendering of the Notion of Purification in Two Elements Included in the Vignettes of Chapters 17 and 125 of the Book of the Dead Lucía DÍAZ-IGLESIAS LLANOS

Taboo - bwt?

Paul John FRANDSEN

Flat-Section Hairpins during the Egyptian Predynastic Period? A Proposal of Identification and Typology

Candelaria MARTÍN DEL RÍO ÁLVAREZ

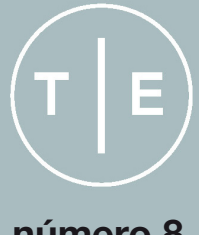

número 8 
Trabajos de Egiptología

Director

Papers on Ancient Egypt

Miguel Ángel Molinero Polo

Universidad de La Laguna, Tenerife, Islas Canarias

Secretaría de edición

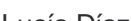

Centro Superior de Investigaciones Cientificas, Madrid

Alba María Villar Gómez

Colaborador de edición I English editorial assistant

Kenneth Griffin

Kenterity Gaino Unido

\section{Consejo de redacción}

Antonio Pérez Largacha

José Ramón Pérez-Accino

Universidad Internacional de la Rioja (UNIR)

José Ramón Perez-Accino
Universidad Complutense de Madrid

\section{Dando agua a los pájaros} Homenaje a Covadonga Sevilla Cueva

Giving water to the birds

An homage to Covadonga Sevilla Cueva

\section{Comité científico}

Marcelo Campagno
CONICET I Universidad de Buenos Aires

Josep Cervelló Autuori

Universitat Autònoma de Barcelona

María José López-Grande

Josep Padró i Parceris

Universitat de Barcelona

M. ${ }^{a}$ Carmen Pérez Die

Museo Arqueológico Nacional, Madrid

José Miguel Serrano Delgado

Evaluadores externos de este número

José Ramón Aja Sánchez | Luis Manuel de Araujo | Juan Antonio Belmonte Avilés | Elena de Gregorio |

Stan Hendryckx | Cristo Manuel Hernández Gómez | Miguel Jaramago Canora | Bill Manley | Alfonso

Martín Flores | Daniel Miguel Méndez Rodriguez | M. ${ }^{2}$ Violeta Pereyra | R. Gareth Roberts | Amelia del

Carmen Rodriguez Rodriguez | José das Candeias Sales | Inmaculada Vivas Sáinz

\section{Fundadores de la Revista}

Miguel Ángel Molinero Pol

José Ramón Pérez-Accino
Covadonga Sevilla Cueva

Editado por I Edited by

Miguel Ángel Molinero Polo | Antonio Pérez Largacha | José Ramón Pérez-Accino

Número 8

2017 


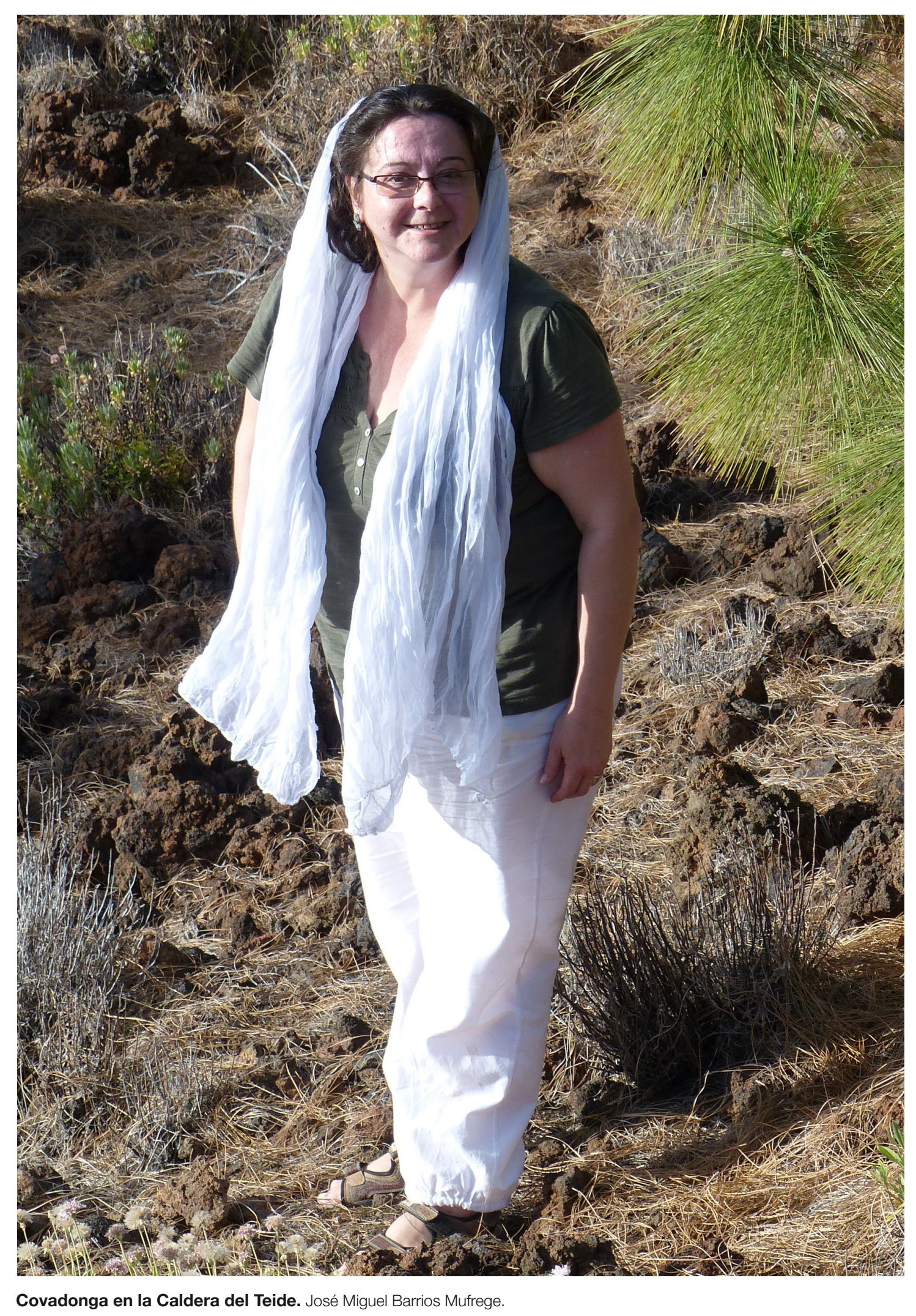




\title{
La ocupación macedónica y la Dinastía Lágida. Impacto político, económico y social
}

\author{
Francisco BOSCH PUCHE
}

Este artículo está dedicado al Egipto de las Dinastías Argéada y Ptolemaica, concretamente a los efectos que tres siglos de dominacion greco-macedonilica provocaron en el pais del Nilo a nivel politico, economico y social. Después de un repaso historico del periodo, se analizan las caracteristicas definitorias de la realeza ptolemaica, haciendo especial hincapié en 1 a se estableció entre éstos y la clase sacerdotal egipcia. A continuación se examina la organización administrativa y fiscal del territorio, junto con los patrones de tenencia de tierra, el papel económico de los templos y el sistema legal del reino. Por ́útimo se describe la composición étnica y estructura social del Egipto ptolemaico, ahondando en la interacción entre sus dos etnias mayortarias, a sabor,

The Macedonian Occupation and the Lagid Dynasty. Pollitical, Economic, and Social Impact

(t) political economic, and social effects that three centuries of Graeco-Macedonian domination had on the Nile country. After an historical overview of the period, the defining features of Ptolemaic kingship are discussed, with particular emphasis on the double role of Hellenistic Next, the kingdon's adminioh that the Lagid rulers embodied, as well as on their relationship with the Egyptian priesthood. temples, and the legal system. Finally the ethnic composition and social structure of Ptolemaic Egyot is assessed, exploring the

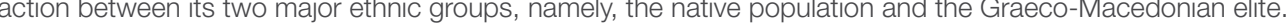

Palabras clave: Periodo Ptolemaico, realeza, politica, economía, administración, sistema fiscal, tenencia de tierra, sistemal legal, sociedad.

Todos aquellos que conocieron bien a Covadonga coinciden en subrayar su pasión por enseñar. Es para mí un honor presentar en su memoria este texto cuya vocación es fundamentalmente didáctica, orientado esencialmente a estudiantes universitarios ávidos por conocer los rasgos políticos, económicos y sociales característicos del Egipto helenístico. Espero que Covadonga no solo lo aprobara, sino que lo considerara una lectura digna de consideración en sus clases.

Ia Segunda Dominación Persa de EgipCa to, inaugurada con la conquista de Artajerjes III en 343 a.C. ${ }^{1}$, vio su fin con la llegada de Alejandro Magno y su ejército en otoño de 332. La ocupación del país del Nilo incorporación de Egipto al Imperio macedónico y, a su vez, sentó las bases para el advenimiento de la Dinastía Lágida, la dinastía más duradera y exitosa de los estados helenísticos por parte del soberano macedonio supuso la

Alejandro y, de hecho, la última y más durade-

1 O bien en 340/339, a juzgar por la nueva propuesta de datación planteada por Depuydt 2010

TdE 8 (2017) - Paginas: 33 - 73

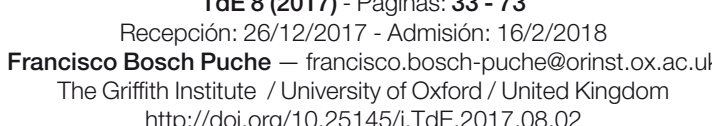


ra en toda la historia antigua egipcia ${ }^{2}$. A pesar de tratarse de una dinastía extranjera, y que en esencia robernó como tal, los soberanos ptolemicos abrazaron varios aspectos de la culolereadicions ancestrales de su tierra de y tradiciones ancestrales de su tierra de adopción, y en sus manos el pais conoció una considerable prosperidad económica, un significativo poder político-militar y una intensa actividad intelectual y artística ${ }^{3}$. Los Ptolomeo convirtieron Egipto en un reino mediterráneo con capital en Alejandría, corazón de un imperio de extensión no comparable en su punto álgido a ninguna de las expansiones imperiales faraónicas precedentes. A estos monarcas, que dejaron en el país una huella más profunda que cualquier otra dinastía foránea anterior, cabe considerarlos justamente como los últimos faraones de Esipto ${ }^{4}$. No en vano, chos elemes chos elemto que la cultura poncibe cono egipcios por excelencia pertenecen precisamente a este periodo final, tan singular y lleno de contrastes y especificidades de la civilización faraónica: es el caso, por ejem plo, de determinados monumentos, como la célebre piedra de Rosetta, documento clave para el desciframiento de la escritura jeroglifica, o los templos ptolemaicos, entre ellos e templo de Horus en Edfu, alabados entre las obras maestras de la arquitectura faraónica; también de ciertos personajes, entre los que la fioura de la última representante de la dinastín, Cleopatra VII, sobresale por encima de resto, sin lugar a dudas uno de los moa de eripcios de todos los tiempos que mayor fascinación ha to as lo y conpos que myor

A pesar de que en toda etapa histórica se pueden distinguir claros elementos de continuidad con respecto a las que la han precedido, y en este sentido el Egipto helenístico

Manning 2010: 31 y 65-66.

3 Sales 2005: 24

4 Vandorpe 2010: 159 y 179 no constituye ninguna excepción, el objetio principal de este artículo es el de centrar la discusión en los elementos de cambio o ruptura, o en otras palabras, el de examinar los efectos que tres siglos de dominar ectos que tres siglos de dominación grecoracedón raones. Los gobiemos de Argédas y Ptolomeos tuvieron un impacto profundo en país del Nilo, el cual se dejó sentir en ámbitos muy diversos. Aquí nos ocuparemos especialmente de las esferas política, económica y social, si bien también será necesario hacer referencia, aunque de manera sucinta, a otros aspectos como por ejemplo el cultual y religioso. Especial atención se dedicará a la monarquía y a los templos junto con sus sacerdocios, indiscutiblemente los dos grandes protagohistas del periodo. En cuanto a la primaistas del periodo. En cuanto a la primera, a dos, se bro hica y, con relación a los segundos, se hará hincapié en su papel economico y en su rol de garantes de tradición y, muy es-

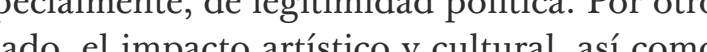
i pape el papel de Alejandría en el mismo, se ha dejado de lado en el presente trabajo al requeri un tratamiento más detenido y específico que desbordaría los límites que nos hemos fijado.

Afortunadamente, para el estudio del Egipto helenístico las fuentes a nuestra disposición son abundantes y de índole diversa. Además de un considerable número de documentos de carácter oficial, como pueden ser los dece cáncter oficial, como de los testimonios de historiadores griegos romanos, como por ejemplo Diodoro SínPlutarco y Dion Casio, fu liodoro Sicura reconstruir la historia política del periodo contamos con una cantidad ingente de papiros y ostraca, redactados tanto en demótico como en griego, la lengua de la nueva adminisración. Esta documentación, frecuentemente reunida en archivos, es esencial para el cstu de la realidad socioeconómica e instituciona del país, pues aporta invaluable y detallada informacion de tipo administate y legal, in parangon con elapas previs de la histoin previas de la historia egipcia o con el resto de estados helenísticos contemporáneos. Ahora bien, cabe señala que su distribución espacial, y hasta cierto punto también cronológica, es bastante irregular, por lo que la imagen que nos ofrece dista de ser completa. La mayor parte de la evidencia papirológica proviene de la depresión de El Fayum; distintas localidades del valle del Nilo también han proporcionado papiros, mientras que éstos son prácticamente ausentes el delta y en Alejontentes de clos man guo, debido a las condiciones desfavorables para su supervivencia (elevado nivel freatico) Por otra parte, los ostraca se concentran básiamente en el Alto Egipto, siendo en este caso la Tebaida, y en especial su capital Tebas, la mejor representada.

\section{1. | Reseña histórica}

Este estudio se enmarca cronológicamente ntre la ocupación de Egripto por parte de Ale jandro Magno en 332 a.C. y la caíla de AlejaJú́ en la consiguente establecimiento de la provincia romana de Aegyptus. Este periodo está re- presentado por dos dinastías distintas: por un ado, la Dinastía Argéada (332-305), integraa por el mismo Alejandro, su hermanastro lipo Arrideo, deficiente mental, y Alejandro IV, su hijo póstumo con la princesa bactiona Roxana, durante la cual Exipto se mantiente como una satraṕa o proving ás del Imin perio macedonico unificado, $y$, por otro la(305-30), que abarcarte de Ptolomeo I, hijo de Lagos -de ahí su denom nación alternativa de Dinastía Lágida- hasta el suicidio de Cleopatra VII, etapa en la que Egipto, ya como reino independiente, vive en constante conflicto político y de prestigio con el resto de estados helenísticos -y, en su fase final, supeditado también a las sucesivas inje- para mantener su suprem Mediterráneo oriental ${ }^{6}$

Después de la victoria de Issos en noviembre de 333 y de la conquista de la costa fenicia y palestina, con los duros asedios de Tiro y Gaza, en otoño de 332 Alejandro Magno se dirigió hacia Egipto, donde fue recibido como un libertador. Sin encontrar resistencia alguna, durante su marcha hacia la capital obtuvo la rendición del sátrapa persa Mazaces, acto que terminaba con poco más de una década de dominio persa y suponía la anexión de Egipto -y de su riqueza agrícola- al Imperio macedónico, el cual pasaba desde entonces a dominar de forma efectiva todas las tierras del Mediterráneo oriental ${ }^{7}$. En Menfis Aleocrifios a los dioses y espeo do por el brazo canópico del Nilo, fundó en hasta 305 .

6 La historia dinástica y política de este periodo se reconstruye ampliamente en Hölbl 2001 [1994]; Huß 2001. La sinopsis aquí presentada se basa fundamentalmente en el primero, si bien también toma en consideración otras síntesis existentes, especialmente Lloyd 2000; Vandorpe 2010.

7 Hölbl 2001 [1994]: 9 
la costa oriental del delta la ciudad de Alejandría, futura capital del reino ptolemaico, que ejercería de vínculo entre el valle del Nilo y el mun jo mediterán y rápidamente se y e vertiŕa en uno de los mayides puertos con-

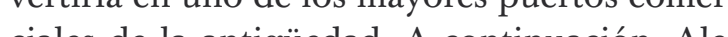
jales de la antigis jandro efectuó la célebre visita al oráculo de Amon en el oasis de Siwa ramificación del culto tebano a Amón-Re pero reconocido como uno de los grandes centros oraculares del dios Zeus por el mundo helénico. La visita, ciertamente una maniobra propagandística perfectamente calculada, supuso para el soberano macedonio no sólo la afirmación de su autoridad como sucesor legítimo de los faraones ante sus nuevos súbditos egipcios, sino también el reconocimiento de su filiación divina ante griegos y macedonios, como de hecho los áclos de Apolo en Dúdima y la sibila de Eritras, a a y de la sibila de Eritras, anbos en Asia Menor, rápidamente así lo confirmarian y comunicarian al mismo Alejandro a su vuelta a Menfis. En la capital, y justo antes de partir hacia la conquista definitiva del Imperio aqueménida, Alejando organizó el gobierno del país y su defensa. De acuerdo con Arriano, dividió la administración civil de Egipto entre dos nomarcas indígenas, Doloaspis -cuyo nombre es en realidad iranio- y Petisis, pero el primero se hizo cargo de todo el territorio después de la renuncia del segundo. Varios macedonios y griegos fueron puestos al mando de las fuer- zas militares y a Cleómenes, un griego originario de la colonia de Naucratis en el delta se le otorgó el cobierno de Arabia y le fue encargada la dirección de de Arema fiscal y la tecaudacion de los tibutos, as como la super vín de la consucción de Alejand ${ }^{9}$. A pevar de que Alejandro op sar de que Alejandro optó por una clara separación de poderes, con inclusion de persona nativo en el sistema de gobierno y con instrucciones explícitas de "permitir a los nomarcas gobernar sus respectivos distritos de acuerdo con las normas establecidas desde antiguo"10 Cleómenes pronto se convirtió en gobernador general ("sátrapa") del país, instaurando un régimen fiscal opresivo y actuando con un alto grado de corrupción y falta de consideración nunca a perder el favor de aunque sin

A la muerte de Alejandro en Babilonia en junio de 323 , ju

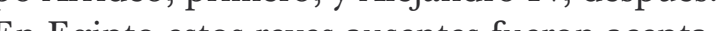
dos como los neyes ausentes fueron aceptadocome los nuevos monarcas, tal como la documentán papirológica, la decoración mural de los templos y las titulaturas faraóncas que les fueron otorgadas así lo ponen de manifiesto ${ }^{12}$. Sin embargo, el poder efectivo de las distintas provincias quedó en manos de a élite militar, a saber, los diádocos o "sucesores" de Alejandro. En su reparto, el general Ptolomeo recibió E Eripto, Libia y parte de Arabia, con Cleómenes como segundo al mando en calidad de hiparca por un breve espacio de Imperio seléucida, con base en Siria y Mesotiempo. Ptolomeo gobernó el país del Nilo como sátrapa durante casidos décadas, periodo durante el cual se produjo el traslado de lado durante pital de Menfs a Alejandía (Gg 1 ) . Esta etapa se carate por el cominzo del conflicto armado entre los sucesores, la prinnera fase de operaciones (321-301) enfrentó a aquellos que intentaban mantener la unidad del imperio contra los que, como Ptolomeo, estaban determinados a forjar sus propios reinos. Ptolomeo no sólo defendió Egipto de dos intentos de invasion (el primero por parte de Pérdicas en 321, como reacción a la apropiación de cuerpo de Alejandro cuando era trasladado a Macedonia para ser enterrado en la necrópolis real de Egas ${ }^{14}$, y el segundo de Antírono en $306)^{15}$ sino que también extendió su terito$y$ los primes inten de ocupacion yalestina, Chipre, Caria y Licia en Asia Meno Palestina, Chipre, Caria y Licia en Asia Menor y tambiên el Egeo . La derrota y muerte de Antígono en Ipsos en zor decidió esta primede la división del imperio, los cuales, anticipando el resultado, habían asumido ya el título de rey $(\beta \alpha \sigma i \lambda \varepsilon v \zeta)$. Esto supuso el comienzo de la segunda fase de operaciones del conflicto de los diádocos (301-281), caracterizada por las luchas entre los separatistas para instituir, mantener o ampliar sus respectivos reinos y cuya consecuencia fue el establecimiento de potamia, y el Imperio ptolemaico, cuyo corazón era Eripto y la Cirenaica; tres contrincantes en una continua partida de poder e in-

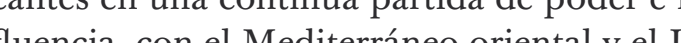
a minaría hast

Con la asunción de la realeza por parte de Ptolomeo se inaugura la Dinastía Ptolemarca (tabla 1). Desde un punto de vista estrictamente político, y de acuerdo con G. Hölb podemos distinguir tres fases en la evolución historica del reino ptolemaico: 1) la "edad de oro" (305-222 a.C., Ptolomeo I a Ptolomeo III), periodo no sólo de formación del reino, sino también en el que el imperio alcanza su máximo apogeo; 2) la etapa de transición (221-204 a.C. Ptolomeo IV) y declive (204(68 a. C. Ptolomeo V y prima pate del reciser mento del poder seléucida y el ascenso de Roma como potencia militar; y 3) el periodo de decadencia (168-30 a.C., Ptolomeo VI a Cleopatra VII), en el cual la autoridad de Roma es un factor determinante en el devenir de los estados mediterráneos ${ }^{18}$.

Las ambiciones expansionistas de los Ptolomeos se focalizaron fundamentalmente sobre dos áreas geográficas: por una parte, los antiguos centros de cultura griega de ciudades griegas de Asia Menor) y, por otra, (68 a.C. Ptomeo V y primera parte del recrisis polica, las difer cascales, el au-

8 Episodio de la breve estancia del soberano en Egipto tratado de forma más amplia y detallada por el conjunto de la tradición clásica y tambiên entre los historiadores actuales en lo referente a sus motivaciones y consecuencias; ver, por ejemplo, Langer 1981; Anson 2003; Collins 2014.

9 Arr., $A n$., 3.5.2-7. También Curt., 4.8.4-5.

10 Arr., An., 3.5.4. También Curt., 4.7.5.

11 Sobre este personaje, ver Le Rider 1997; 2003: 238-265

12 Dos estudios recientes sobre la actividad constructiva de la Dinastía Argéada los constituyen Chauveau y Thiers 2006: esp. 390-399; Ladynin 2014. En cuanto a los protocolos onomásticos de sus integrantes, ver Bosch-Puche 2013; 2014 (Alejandro Magno); De Meulenaere 1991; Blöbaum 2006: 424-425 (Filipo Arrideo); Blöbaum 2006: 426428 (Alejandro IV).

13 Estela del sátrapa [311 a.C., Museo Egipcio de El Cairo, CG 22182], 1. 2 = Urk. II, 13.3-5 (gobierno efectivo de

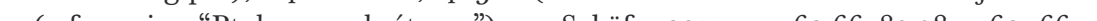

14 Fl cuerpo, considerado un activo proparandístico y de estatus sin igual, fue enterrado provisionalmente en Menfis poco después trasladado a la nueva capital.

15 Lloyd 2000: 396

16 Hölbl 2001 [1994]: 304.

17 Hölbl 2001 [1994]: 20-22.

18 Hölbl 2001 [1994]: esp. 304-306 (síntesis). 


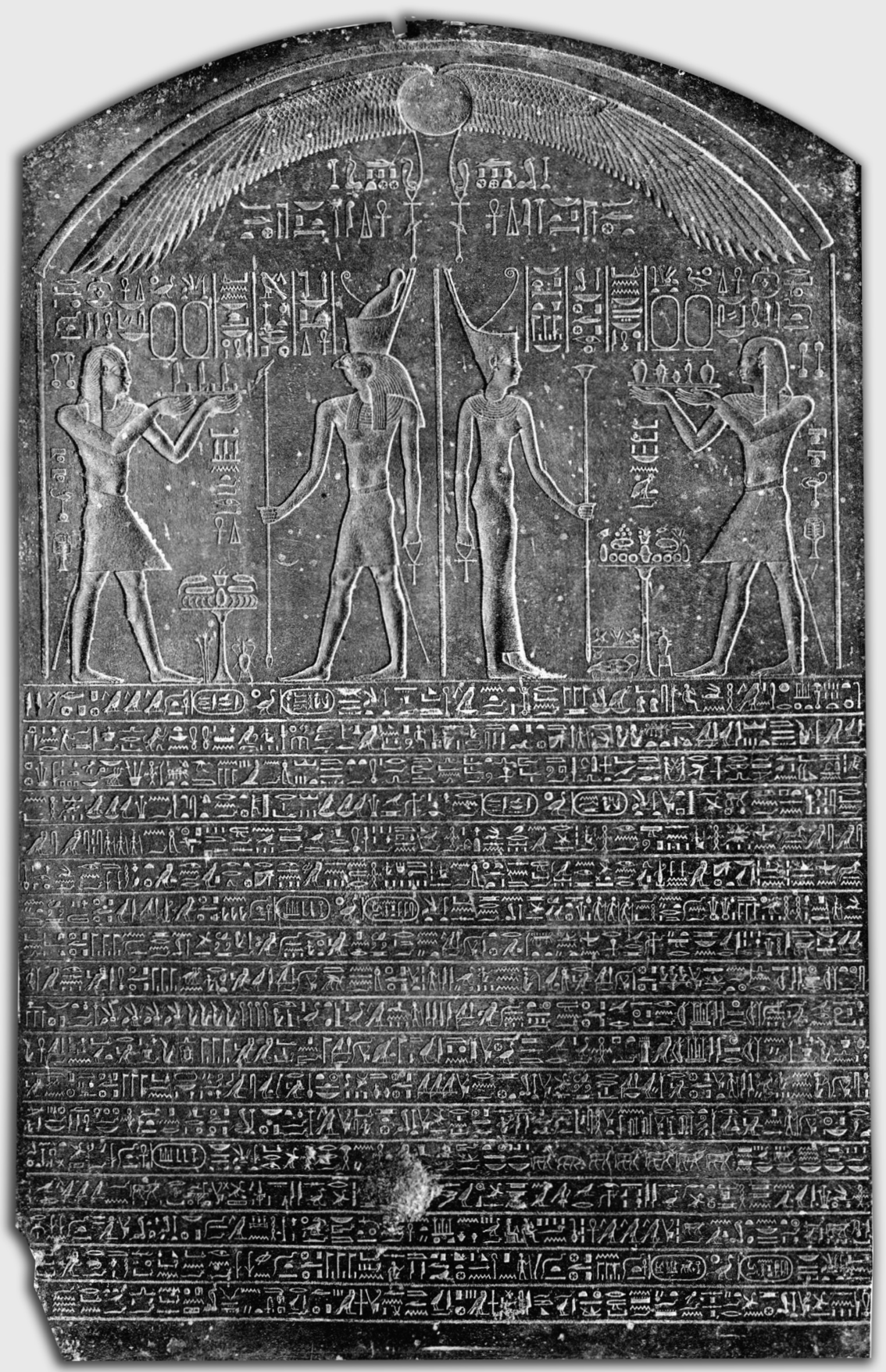

\begin{tabular}{|c|c|c|}
\hline Ptolomeo I Soter & $305-282$ & \\
\hline Ptolomeo II Filadelfo & $282-246$ & \\
\hline Ptolomeo III Evergetes & $246-221$ & \\
\hline Ptolomeo IV Filopator & $221-204$ & \\
\hline Ptolomeo V Epifanio & 204-180 & \\
\hline \multirow{2}{*}{ Ptolomeo VI Filometor } & 180-164 & $\begin{array}{l}\text { [180-177 con Cleopatra I; } 177-170 \text { independiente; } \\
\text { 170-164 con Cleopatra II y Ptolomeo VIII] }\end{array}$ \\
\hline & $163-145$ & [con Cleopatra II] \\
\hline Ptolomeo VII Neo Filopator & & [nunca reinó] \\
\hline \multirow[b]{2}{*}{ Ptolomeo VIII Evergetes II } & $170-163$ & $\begin{array}{l}\text { [170-164 con Ptolomeo VI y Cleopatrall; 164-163 } \\
\text { independiente] }\end{array}$ \\
\hline & $145-116$ & $\begin{array}{l}\text { [145-141/140 con Cleopatra II; } 141 / 140-132 \text { con } \\
\text { Cleopatra II y Cleopatra III; 132/131-127 reinado in- } \\
\text { dependiente de Cleopatra II y reconquista del reino } \\
\text { por parte de Ptolomeo VIII; } 27 .-125 \text { con Cleopatra II; } \\
124-116 \text { con Cleopatra II y Cleopatra III] }\end{array}$ \\
\hline Ptolomeo IX Soter II & 116-107 & $\begin{array}{l}\text { [primer reinado: } 116-115 \text { con Cleopatra II y Cleopatra } \\
\text { III; } 115-107 \text { con Cleopatra III] }\end{array}$ \\
\hline Ptolomeo X Alejandro I & $107-88$ & [107-101 con Cleopatra III; 101-88 con Berenice III] \\
\hline Ptolomeo IX Soter II & $88-81$ & [segundo reinado] \\
\hline (Cleopatra) Berenice III Filopator & 80 & [primero independiente, después con Ptolomeo XI] \\
\hline Ptolomeo XI Alejandro II & 80 & \\
\hline Ptolomeo XII Neo Dioniso & $80-58$ & [primer reinado] \\
\hline (Cleopatra) Berenice IV Epifania & $58-55$ & [58-57 con Cleopatra VI Trifena] \\
\hline Ptolomeo XII Neo Dioniso & $55-51$ & [segundo reinado] \\
\hline Cleopatra VII Filopator & $51-30$ & $\begin{array}{l}\text { [sucesivamente con Ptolomeo XIII, Ptolomeo XIV y } \\
\text { Ptolomeo XV] }\end{array}$ \\
\hline Ptolomeo XIII Filopator & $51-47$ & [con Cleopatra VII] \\
\hline Ptolomeo XIV Filopator Filadelfo & $47-44$ & [con Cleopatra VII] \\
\hline Ptolomeo XV Filopator Filometor César / Cesarión & 44-30 & [con Cleopatra VII] \\
\hline
\end{tabular}

Figura 1: Estela del sátrapa, Museo Egipcio de El Cairo, CG 22182 (Kamal 1904-1905: II, pl. LVV). 
Siria-Palestina (oficialmente "la provincia de ping elcontrol de Celesina en zor, la cual permahijo y sucesor Ptolomeo II fue una figura cenSenung Siria y Fenicia" o Celesiria para los historia.

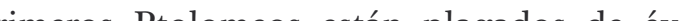
en en a necería anexionada al mperio ptolenaico durante casi un siglo , si bien la reclamación seléucida sobre este territorio nunca cesó hecho que explica el desarrollo de hasta seis Guerras Sirias entre los reinados de Ptolomeo II y Ptolomeo VI. El primer Lágida también reintegró de forma definitiva Chipre al imperio en 295-294 y, al frente de la Liga Insular desde finales de su reinado, fue capaz de establecer una hegemonía ptolemaica en las Cícladas, la cual se prolongaría durante tres décadas. Su cijo y su historia de la dinatí. A nivel cena e como veremo istrativa y ecómica de Egipto $y$, en nistrativa y económica de Egipto y, en cuanto a la política exterior, ya desde comienzos de su reinado reforzo la supremacía ptolemaica en las zonas costeras del oeste y especialmente del sur de Anatolia, con importantes ganancias territoriales en Caria, Licia, Panfilia y partes de Cilicia. También estableció bases y guarniciones en distintos puntos del Egeo. En el Levante tuvo que hacer frente a la Primera Guerra Siria (274-271), reacción seléucida a la xtensión de los dominios ptolemaicos en Asia Menor y cuyo resutado supuso la anexín de enicia al Imperio ptolemaico, y tambićn a só un cariz más in (260-253), conflocto que concluyó de forma menos favorable con puso una disminución de la hegem, lo que su(talaso

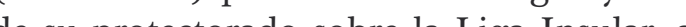
como pra pectida de distia liga Insular, asi como la pérdida de distintos enclaves gandos previamente en Anatolia. Ptolomeo dideró también una importante expedición a la Baja Nubia en $c$. 275, cuya consecuencia fue la instauración de la autoridad administrativa ptolemaica en el Dodecasqueno "(Distrito de) los doce esquenos" de este modo una zona de contención o seguridad de unos $125 \mathrm{~km}$ entre la frontera sur de Egipto en Elefantina y el reino de Meroe, fundamental además para el control de rutas comerciales, el acceso y explotación de materias primal -pripip phe fic africanos para la guerra. Estos mismos incentivos económicos y militares están también detrás de la reapertura del viejo canal persa que conectaba el brazo pelúsico del Nilo y el golfo en el Mar Rojo y Arabia, con la fundación de un destacado numero de enclaves comerciales portuarios y defensivos. Con Ptolomeo III e Imperio ptolemaico alcanzó su máxima expansión. Por una parte, este soberano reincorporó la Cirenaica gracias a su matrimonio con Berenice II, hija del rey Magas de Cirene hermanastro de Ptolomeo II que se hab́a rey con el apoyo seléucida. Por (2) su victoria en la Tercera Guerra Siria (246-241) supuso la consolidación del

20 Además de su importancia estratégica para la defensa de Egipto y de la provincia ptolemaica de Chipre -rica en arábiga (ruta de las especias).

El esqueno (Gyoivos) fue una unidad de longitud griega, equivalente al itrw egipcio y con una extensión de 60 estadios, aunque su valor no fue absoluto. a derrota de la flota egipcia en Cos, lo que sude Suez, así como de la presencia ptolemaica metales-, su ocupación suponía grandes beneficios económicos, a saber, la explotación de los recursos madereros dominio ptolemaico en el sur de Asia Menor, la anexión de Jonia, los Dardanelos y el sur de Tracia e importantes ganancias territoriales en la costa norte de Siria, incluyendo Seleucia Pien (el puerto de Antioqú), o diho en otras palabras, elcontol de todo el liTor Libia, lo que asegurara la suprecta tibia, lo que aseguraría la supremacía cadas más. La expansión ptolemaica podría haber sido incluso mayor de no ser por el estallido de una revuelta egipcia en 245 que interrumpió la campaña oriental ${ }^{22}$. Ptolomeo III continuó también la política intervencionista iniciada por sus predecesores en Grecia para contrarrestar a Macedonia, liderando y subsidiando primero a la Liga Aquea y apoyando después a Esparta Asimismo nuevas ban

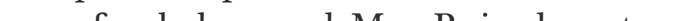
fueron fundadas en

La llegada al trono de Ptolomeo IV inaugura la segunda fase en la evolución histórica de la dinastía. Desde el punto de vista de la política exterior, durante esta fase el Imperio ptoleciones hegemónicas en favor de una política que abogara por el equilibrio de poderes. El periodo se inaugura, sin embargo, con la importante victoria egipcia en la batalla Rafia, que puso fin a la Cuarta Guerra Siria (219-217) y que, a pesar de algunos avances seléucidas ciera en manos permaneco ( ra la falange fue fundamental para el exito de operaciones militares; sin enbargo, el estecimiento de esta nueva clase militar indigena traería graves consecuencias en los años ptolemaica en la región durante cuatro démaico se vio forzado a abandonar sus ambien el Levante, permitió que Celesiria permane- venideros para la estabilidad interna del país, legando a protagonizar varios levantamientos en el delta. De hecho, la harmonía intern que había garantizado una dinámica y exitoa política exterior durante la edad de oro, rompió en esta secunda fase de la historia de la dinasta, situación que se agravarla todavia cia Las causa del declivute o de decadencol ter ptomaiconstantes as en el seno de la familia reinante, agudizaas por la implicación de la poderosa e inluyente población alejandrina, la ambición desmedida de cortesanos de alto rango que aprovecharían la debilidad dinástica para favorecer sus propios intereses $y$ especialmente vorions IV como un personaje incapaz en manos de cos consejes yinistros Sosibio A Agaclos de Samos, quienes tendran an parien un panado de Ptolomeo V, el cual llegó al trono con apenas seis años de edad ${ }^{24}$. Una de las principales consecuencias de la crisis institucional fue la erupción del alzamiento interno, frecuentemente presentado como una reacción nacionalista frente al gobierno extranjero, pero cuyas causas radican esencialmente en el malestar social de la población nativa debido los elevados costes -humanos y económicos (presión fiscal)- que la financiación tanto de (polícica exterior como de la vida en la corte arreaba $A$ fina de su gobierno, Ptolte IV no solo Auvo que hace frent a los ya mencionados levantamientos de máchimoi en el más en el periodo subiguie o de decade con son diversas, pero el conflicto dinástico intrigas y a menudo sangrientas luchas intestmo de Roma ${ }^{23}$. Polibio prenta a Ptomeo pel protagonista en los primeros años de rei-

22 Las revueltas nativas y los problemas internos que azotaron el reino hasta la conquista romana, los cuales aparece enumerados en los párrafos sucesivos, se analizan en detalle en McGing 1997; Veïsse 200 Lloyd 2000: 418-419; Vandorpe 2010: 164-165 24 Préaux 1965. 
delta, regularmente apoyados por la sobreexplotada clase agrícola, sino también a una oposición creciente en el sur del país, uno de cuyos primeros signos fue la internupcio de cuyos pinion de las obras en ter $\mathrm{V}$. joven Ptolome Egipto, la llam de la Tebaida (206-186), con el establecimiento de un estado faraonico independiente con capital en Tebas y el apoyo militar puntual de Nubia, gobernado sucesivamente por dos reyes nativos llamados Horunnefer (205-199) y Ankhunnefer (199-186) ${ }^{25}$. Durante este periodo de sublevación se observa la paralización, e incluso destrucción, de varios proyectos ptolemaicos de construcción y restauración de templos en la región. Ankhunnefer fue finalmente derrotado en batalla en 186, aunque inte tado poco después, posi tado poco despes, posible aun evitar nuevo alo cos de rebelión en el delta tamoinn fueron finalmente reprimidos con dureza. El reinado de Ptolomeo V sufrió, sin embargo, sig nificativos reveses a nivel extrior. Durante la Quinta Guerra Siria (202-195), Egipto tuvo que hacer frente a ataques simultáneos de los reyes seléucida y macedonio, con la pérdida de las posesiones ptolemaicas en Siria y Fenicia, Asia Menor y Tracia; sólo las provincias de Chipre y la Cirenaica, así como algunas bases en el Egeo, se mantuvieron como parte del imperio. A la muerte de Ptolomeo V, suesposa Cleopatra I Sira le sucedió en el gobierposa Clepara I sira le sucedió en el gobierpo (180-170), al pargo de sus tes hijos de po (180-176), al cargo de sus tres hijos de corta edad: Ptolomeo VI, cl futuro Ptoloneo VIII y Cleopatra 1I. Después de su fallecimiento, fue reemplazada por varios tutores incompetentes, los cuales dirigieron el reino hasta la Sexta Guerra Siria (170/169-168), durante la cual el rey seléucida Antíoco IV, hermano de

25 Hurgonafor y Chaonnofris respectivamente en la documentación griega; ver Pestman 1995
Ptolomeo VI terminó por enmendar las co- de este suceso ${ }^{27}$. La muerte de Ptolomeo VIII sas con Ptolomeo VIII, quien tuvo que contentarse con el gobierno de la Cirenaica. Durante su reinado Egipto recuperó el conica. Du la Ba Nubia perdido desde la Revitro de la Baja Nubia perdido desco la Revuelta de la Tebaira. Sin e incluso intentó reconquistar la Celesina. Sin enbargo, la muerte inesperada del soberano en Siria en 145 supuso el final de las ambiciones ptolemaicas en la región y el retorno de Ptolomeo VIII a Alejandría, donde tuvo que hacer frente a un nuevo intento de golpe, esta vez liderado por el comandante Galaistes (141/140). La política matrimonial de Ptolomeo VIII condujo el reino a la guerra civil (132-124), la cual enfrentó a los partidarios de Cleopatra II (viuda de Ptolomeo VI y después esposa de Ptolomeo VIII) con los de Ptolomeo VIUI y Cleopatra III (hija de Ptolom VI y Cleoptra II Y III (hija de Ptolom esposa de Ptolonco vill). Finalnente, en 124 llegó la reco (mión de Ptolomeo VIII y sus dos esposas (madre e hija), con el consiguiente establecimiento de un triple gobier no conjunto ${ }^{26}$. Por mucho tiempo se ha asumido que un nativo llamado Harsiese habría aprovechado la situación en la corte para instigar una revuelta indígena en Tebas y, refugiado después en el Egipto Medio, proclamarse rey en 131-130 -el último indígena en ostentar el título de faraón-, aunque en la actualidad de este suceso ${ }^{27}$. La muerte de Ptolomeo VIII ticas, con la ambiciosa Cleopatra IUI y us hijos Ptolomeo IX y Ptolomeo X como protajos Ptolomeo IX y Ptoloneo X como prota-

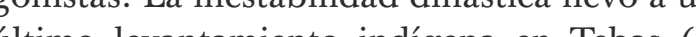
88-86), el cul fue indigena en Tebas (c. 88-86), el cual fue reprinido con gran severdad por parte de Ptolomeo IX, aunque el descontento interno generalizado acompañarí desde entonces a la dinastía hasta el fin de sus días. Gracias a la intervención de Roma, e el año 8o Ptolomeo XI, hijo de Ptolomeo X, sucedió a su tío Ptolomeo IX en el trono, pero su gobierno apenas duró unos días; el monarca fue asesinado por una turba alejandrina. Ptolomeo XI, que debía su reino a Roma, supuestamente lo legó a su benefactora en testamento como agradecimiento, si bien algunos autores señalan a Ptolomeo X como (1) do parece indicre que, en realidad, este be poda haberse fase, en realidad, éste bien podria haberse falsificado en Roma para just ficar la creciente injerencia política del Senado en los asuntos egipcios. De hecho, a partir de ese momento y hasta el final de la dinastía el papel de Roma sería decisivo, empezando por Ptolomeo XII en su disputa con los alejandrinos, con cuantiosos sobornos y préstamos de por medio. Ante la pasividad del soberano, Roma, que ya controlaba la Cirenaica (desde 96 , convertida en provincia en 74 ),

26 Ptolomeo VII Neo Filopator es una figura controvertida en el seno de la dinastía. Al parecer nunca reinó te de que su madre hubiera intentado deponer a Ptolomeo VIII y proclamarlo rey (ver, por ejemplo Hölbl 200 [1994]: 195, 197-198 y 202-203). Otros autores consideran que se trataría de Ptolomeo Eupator, hijo de Ptolomeo VI y Cleopatra II y corregente con su padre por un brevísimo espacio de tiempo, o incluso algún otro príncipe secundario también llamado Ptolomeo. Por tradición, y para evitar confusión, la numeración de los soberanos ptolemaicos se ha mantenido inalterada en la producción historiografica, eliminando a Ptolomeo Vlil de la lista pero sin variar el número asignado a los monarcas posteriores, aunque existen algunas discordancias, especialmente en sobras más antiguas.

27 Veisse 2009; Vandorpe 2010: 166

28 Para una discusión de las fuentes, ver van't Dack 1989: 156-160. 
anexionó también Chipre $\left(5^{8}\right)^{29}$. Por último, Cleopatra VII, la única integrante de la Dinastía Lárida que aprendió egipció de la pleó su inteligencia carisma y encanto pleó su inteligencia, cario y

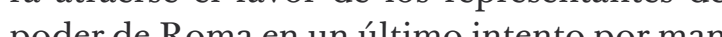
poder de Roma en un último intento por mande Egipto. Con el apoyo de Julio César (4844), consiguió imponer su autoridad frente a sus hermanos Ptolomeo XIII y Ptolomeo XIV con el de Marco Antonio (41-30), logró incluso recuperar fugazmente el control ptolemaico en el sur de Asia Menor y en la región siriopalestina. La derrota de las flotas de Marco Antonio y Cleopatra en la batalla de Accio el 2 de septiembre de 31 acabó con el sueño de formaico en la cuenca mediteránea orientl. La entrada tiunfal de Octaviano en Alejandra 1 de agosto del ano 30 a C y los suicidios de Marco Anto dio jo a.c. y los suicidios de Marco Antonio primero y Cleopatra después supuso el final de la Dinastía Ptolemaica, la desaparición delútimo reino helenistico sucesor del imperio de Alejandro Magno y, en definitiva, el comienzo de la historia de la provincia romana de Aegyptus.

\section{I La realeza ptolemaica}

La característica principal de la ideología real ptolemaica la constituye el hecho de que el monarca, como los habitantes de su reino, tuvo dos facetas: una greco-macedónica y otra egipcia/faraónica ${ }^{31}$. Por una parte, el soberano ptolemaico fue un rey helenísti-

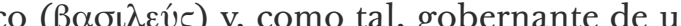
dite extranjera que habitaba dís de una a su vez, de disintos pueblos súbditos nis ${ }_{32}$. El concepto heles sore no y se crír en líder carisarnaba al esso, y se erigía en lider carismático, victorioso, salvador, liberador, protector, benefactor $\mathrm{y}$ creador $\mathrm{y}$ garante de fertilidad y riqueza ${ }^{3}$ Por otra parte, el monarca fue también faraón es decir, heredero de una tradición de gobierno ancestral, formulada esencialmente en términos míticos y cultuales y específicamente ligada al territorio egipcio y a su población nativa ${ }^{34}$

La monarquía ptolemaica fue, ante todo una "cuestión de familia", como así lo evidencian el uso sistemático de ciertos antropónimos (Ptolomeo en el caso de los varones; Arsínoe, Berenice y Cleopatra en el de las mujeres) y la adopción de determinados epítetos de culto (Filadelfo, "el/la que ama a su hermano/a"; Filopator, "el/la que ama a su padre"; Filometor, "el/la que ama a su madre") (tabla 1). Desde un buen comienzo, la estabilidad de la amilia real fue reforzada con la práctica de asociar un hijo y heredero al trono del padre antes de su fallecimiento (corregencia) y con la introducción del matrimonio consanguíneo, fundamentalmente entre hermanos ${ }^{35}$. Esta segunda costumbe fue iniciada por Ptolome II

29 El erosionado reino seléucida también había caído en manos de Roma; Pompeyo había creado la provincia romana de Siria en 64 . El control ptolemaico del Dodecasqueno cesó en el siglo I a.C., si bien algunos proyectos constructivo

30 Plu., Ant., 27.4-5.

11 Para el estudio de la realeza ptolemaica, ver especialmente Heinen 1978; Koenen 1983; 1993; Mooren 1983; Peremans 1987; García Moreno 1992; Gómez Espelosín 1992; Samuel 1993; Pfeiffer 2016.

32 Lloyd 2000: 407

33 Hölbl 2001 [1994]: 9

hermana Arsínoe II, estableciéndose paralelos con arquetipos tanto de la mitología oriega (Zeus y Hera) como egipcia (Osiris e Isis) ejercicio del poder real al más alto nivel a e ejercicio del po dinas re be hecho, nive a las mujeres de la dinastia. De hecho, una de las caracteristicas que distingue a los Ptolomeos de otras monarquias antiguas es precisamente la importancia de la posición de la reina en la representación y concepción de la dinastía; a partir del siglo II a.C. el papel político de algunas de ellas fue determinante, llegando a gobernar conjuntamente con sus esposos o incluso a reinar de forma independiente, como es el caso de Cleopatra II, Berenice IV o Cleopatra $\mathrm{VII}^{36}$

Los Ptolomeos siempre se consideraron a si mismos macedonios e hicieron todo lo posible a a la hora de difundir su imagen en el exterior y, en especial, en el mundo griego ${ }^{37}$. Establecieron su residencia en Alejandría, ciudad que desde comienzos del periodo fue empleada como arma ideológica en su lucha por el estatu y el prestigio con el resto de estados helenísticos. En efecto, la capital ptolemaica, con sus monumentos -entre ellos, el faro, el barrio de los palacios y la tumba de Alejandro- e instituciones culturales -especialmente el museo con su célebre biblioteca, que impulsarían a la ciudad como centro de ciencia tecnología y erudición literaria-, se convirtió en escapate de
Los monarcas ptolemaicos aprovecharon cualquier oportunidad para exhibirlos, como por ejemplo con ocasión de las Ptolemaia (o Ptolemaieia), un festival instituido por Ptolo to en honor a sus progitor Ptolom Iy en hon a sus progenitores Ptolomeo Iy Berenice I y celebrado por pring mente en $279 / 278$. Este festival, que se celebraría cada cuatro años, llegando a rivalizar en popularidad con los Juegos Olímpicos, en el que se invitaría a participar a distinto estados griegos, se elaboro más y más con cada nuevo Ptolomeo, convirtiendose en la festividad definitoria de la Dinastía Ptolemaica. Constaba de sacrificios, banquetes, todo tipo de competiciones y espléndidas procesiones, empleados como exaltación de las raíces dionisíacas de la familia real $y$, en definitiva, de su magnificencia y opulencia $\left(\tau 0 u \varphi^{40}\right)^{40}$

El festival de las Ptolemaia, convertido en instrumento ideológico para la legitimación y divinización de la monarquía, estuvo estrechamente relacionado con el establecimiento del culto dinástico de la casa real ptolemaica. Ptolomeo I preparó el camino al instituir un culto a Alejandro como dios imperial con su propio sacerdote -paralelo al culto al soberano macedonio como fundador de la ciudad de Alejandría- y al declarar su descendencia de Zeus y difundir rumores de que era hijo secreto de Filipo II y, en consecuencia, hermanastro de Alejandro ${ }^{41}$. Ptolomeo II, por un lado, elevó a sus difuntos progeniton go divino como los "dioses salvadores" y, por

34 Hölbl 20o1 [1994]: 22

35 Bowman 1986: 23-24

Hazzard 2000: 81-159; Ashton 2008; Roller 2010; Carney 2013; Clayman 2014; Bielman Sánchez y Lenzo 2015. 37 Pfeiffer 2016: 4 .

8 Lloyd 2000: 404-406. Para la ciudad ptolemaica, ver fundamentalmente Fraser 1972; Ballet 1999; McKenzie 2007: $19-118$.

39 Dunand 1981; Rice 1983; Hazzard 2000: 59-79; Lloyd 2000: 406-407; Thompson 200o; Hölbl 2001 [1994]: 94; Pfeiffer 2008a: 71-73.

40 Sobre la touфí ptolemaica, ver Gouëssan 2013; Pfeiffer 2016: 9-10. 
otro, declaró su propia divinidad y la de su esposa Arsínoe II en 272/271 como los "dioses hermanos", vinculando su culto directamente al de Alejandro e inaugurando una práctica que sería seguida por las parejas gobernantes venideras, empezando por Ptolomeo III y su esposa Berenice II, que se incorporarían al culto como los "dioses benefactores", y, a continuación, por Ptolomeo IV y Arsínoe III que lo harían como los "dioses que aman a su padre". En tiempos de Ptolomeo IV este culto dinástico recibió su forma final con la edificación de un imponente mausoleo para Alejandro y los reyes ptolemaicos en el barrio de los palacios en Alejandría, con la adhesión del culto de Ptolomeo I y Berenice I, el cual se había mantenido independiente desde su instarion, al cur Hermiou, fundada por Ptolomo I en el Alto E i Egipto, en el cual el primer Ptolomeo ocupó la posición de Alejandro ${ }^{2}$. El culto fue mantendo por sacerdotes elegidos de entre las famlias macedonias y griegas más prominentes de país, incluyendo miembros de la casa real, tanto en Alejandría como en Ptolemais, los cuales, en calidad de "sacerdotes epónimos" según la tradición de las polis griegas, figuraron durante los dos primeros siglos de dominio

ptolemaico en las fórmulas de datación de contratos y documentos oficiales, tanto criego como en demótico, después de la indicación del ño de reinad ${ }^{43}$. Además de este culto colectivo, numerosos cultos individuates de tipo cerdocios específicos, se establecieron tam bién para distintos mi, se establecieron tamdistintos mienbros de la fanilia real din especial, con relación a las mujeres de la I4t $\mathrm{II}^{44}$ y Cleopatra III ${ }^{45}$. Ramificaciones de estos culos se documentan, asimismo, en las poseexteriores del Imperio ptolemaico ${ }^{46}$.

Ahora bien, como se ha indicado anterio mente, los Ptolomeos fueron también faraones; la existencia de titulaturas reales de estio egipcio para cada uno de los integrantes de a dinastín 47 y su representación en los relieves de los templos autóctonos según los cánes

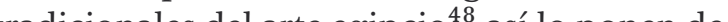
ma las reinas ptolenicas conta os ono escenas dos encios osposos o incluso oficiando ritos por sí solas ${ }^{50}$ (fig. 2), clara consecuencia en ambos casos de la importancia de su rol, tanto desde el punto de vista político como cultual. Esto demuestra que los Ptolomeos, a pesar de su origen extranjero,

41 Paus., 1.6.1.

42 Para el culto dinástico, ver fundamentalmente Pfeiffer 2008a; 2016: 5-6, quien distingue entre el culto al soberano y la variante dinástica. También Fraser 1972: I, 213-226; Hölbl 2001 [1994]: 91-95, 169-173 y 285-288.

3. Ijsewijn 1961; Clarysse y van der Veken 1983

44 Hölbl 2001 [1994]: 95 y 103; Minas 1998.

5 Hölbl 2001 [1994]: 286-288.

46 Hölbl 2001 [1994]: 96 y 288

47 Ver los repertorios onomásticos establecidos por Gauthier 1916; Kurth 1982; von Beckerath 19992; Hallof 2010; Engsheden 2016; y los estudios sobre su significación de Hölbl 1992; 2001 [1994]: 79-80 y 164; Sales 2005: 131-18

8 Sales 2005 : $267-294$

49 A las referencias citadas anteriormente, añadir Hölbl 2001 [1994]: 85 y 280-281; Eldamaty 2011.

o Hölbl 2003; Minas 2005.

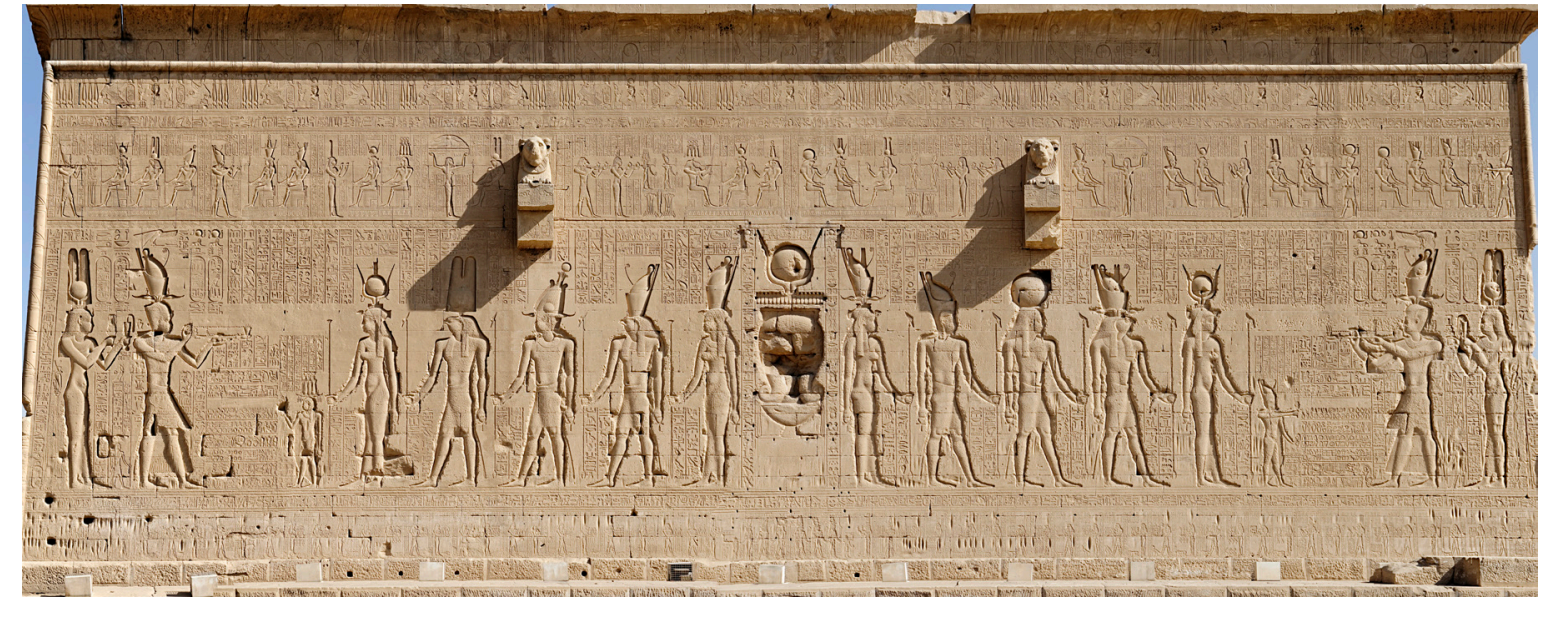

Figura 2: Templo de Hathor en Dendera, muro trasero (@) Manna Nader, Gabana Studios Cairo).

y como ya ocurrió con los reyes ausentes de la Dinastía Argéada, e incluso anteriormente con los monarcas persas de la Dinastía XXVII fueron aceptados y presentados como los soberanos legítimos de Egipto e insertados en la ideología faraónica tradicional sin problemas. En el Periodo Ptolemaico se documenta una intensa actividad de construcción, restauración y decoración de santuarios indígenas, mayormente en el valle del Nilo -con la excepción del área tebana, que sólo recibió excepcion del áma tebana, que so una ation de áre segunda mitad de la dinstí, es decir, coincidiendo con los periodos de declive y decadencia del poder real ${ }^{51}$. Especial mención merece en este sentido el templo de Horus Behdety en Edfu (fig. 3), que puede ser considerado como uno de los símbolos religiosos del gobierno ptolemaico, con actividad constructiva desde Ptolomeo III (237) hasta Ptolomeo XII (57) lo que lo erige en verdadera obra dinástica ${ }^{52}$. A

51 Para un repaso de dicha actividad, ver especialmente Arnold 1999: 143-224 y 320-323; Hölbl 2001 [1994]: 85-88, 160162 y 257-279; Bagnall y Rathbone 2004

52 Manning 2003b. Los Ptolomeos conservaron como sancta sanctorum una capilla preexistente de Nectanebo II (Dinastía XXX), afirmando de este modo la contin mediados del siglo I a.C., el templo de Hatho en Dendera tomó el relevo a Edfu, convirtiéndinastia (fig. 2). Este santuario se completaría en Época Romana, algo que también ocurriría 列 se inició en tiempos de Ptolomeo II, y con el santuario doble de Haroeris y Sobek en Kom Ombo y el templo de Khnum en Esna, en amcos intensa actividad edilicia desde (os reina cos ie Ptolomeo VI y Ptolomeo VIII. Estos monumentos presentan ciertas innovaciones arquitectónicas, en muchos casos con precedentes que se remontan a la Dinastía XXX o incluso anteriores y que perdurarán en el Periodo Romano. Entre las más destacadas debemos mencionar la introducción de un pórtico semiabierto en la parte delan(pronaos), frecuentemente con muros pantalla y dinteles quebrados sobre la puerta de entrada; la existencia de una capilla dose en el último proyecto a gran escala de la 
elevada con patio abierto para la celebración de los festivales de año nuevo (uabet); la edificación de casas de nacimiento independiendivinas y desinadas a la conmeno divinas y destina a la conculto de trian del (a) pe, la adecuación del muro trasero del templo, justo detrás del santuario interno que conple jacio de devoción popular (fig. 2); la utilización de columnas con una enorme variedad de capiteles florales compuestos; y, por último, el empleo del aparejo isodómico y de la anatirosis como sistema de unión de los bloques. Estas novedades físicas van acompañadas de un rico desarrollo teológico en varios centros religiosos, la complicación del sistema escriturario jeroglífico, con la introducción de un gra número de nuevos ignos y la multipli gran de sus valores $y$ en la fase final del periodo, de sus valos ye en la fase fin delo periodo, la utilizacion de cartuchos en blanco -o bien inscritos simplemente con el término $\mathrm{pr}^{-3}$, "faraoon" -, testimonio de la conversión del soberano en una figura puramente ritual y reflejo, en algunos casos, del conflicto dinástico ${ }^{53}$. Estos programas constructivos en los santuarios egipcios están relacionados también con la voluntad, y necesidad, de controlar el territorio y, al mismo tiempo, evidencian la colaboración -o negociación- que se estableció entre la corona y las poderosas élites locales, y muy especialmente la clase sacerdotal, depositaria y custodia de la tición dición ancestr te de legitimación política. Con motivo de de-

terminadas celebraciones religiosas, como por ejemplo festividades señaladas del calendario eripcio, la inauguración de templos ola instalación de anima saon des to Ptolomestaeres a otros centros del teritorio egipcio ( $($ $\omega \alpha)$. Los soberanos tambicn apoyaron econónicamente a los templos y a sus cultos mediante exoneración de ciertos tributos, la donación de tierras y, muy especialmente, el pago de una prestación anual $(\sigma u ́ v \tau \alpha \xi \xi)^{55}$, asegurándose a cambio la aquiescencia de la clase sacerdotal y, debido a su influencia, por extensión, de la población en general. Este acercamiento de la monarquía a la élite religiosa egipcia se acrecentó desde finales del siglo III a. C. coincidiendo con la perdida de territorios e influcic en y la consiguente urgen de asenu orienta

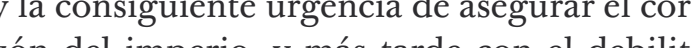
zón de impeio, y mís ta de an el debilitaliństicas y la apaicín de conflico disputas dinásticas y la aparición de conflictos internos en territorio egipcio ${ }^{56}$. Ahora bien, un ejem plo temprano de dicha colaboración la consttuye la figura de Manetón de Sebennitos, autor de obras en griego sobre historia faraónica (los célebres Aegyptiaca) y religión egipcia para Ptolomeo $\mathrm{II}^{57}$, y quien supuestamente habria colaborado ya con Ptolomeo I en el establecimiento del culto sincrético a Serapis, patrón de la dinastía y de la ciudad Alejandría ${ }^{58}$ L clave de esta interacción entre los robernantes ptolemaicos y el estaónento sacerdotal la hallasacerdotes de Ptah en MenEsipto y con am-

3 Arnold 1999: 144-154 y 277-304; McKenzie 2007: 125-136; Clarysse 2010: 275-277.

54 Clarysse 200oa.

55 Si bien también disponemos de algunos ejemplos de evergetismo privado; ver Quaegebeur 1979: 713-715; Thiers 2009: 241-243

${ }_{5} 6$ Para la relación de los Lágidas con los sacerdocios egipcios, ver principalmente Huß 1994; Gorre 2009; AgutLabordère y Gorre 2014: 36-51.

57 Dillery 1999; 2013; 2015; Sales 2005: 71-98; Gozzoli 2006: 191-225.

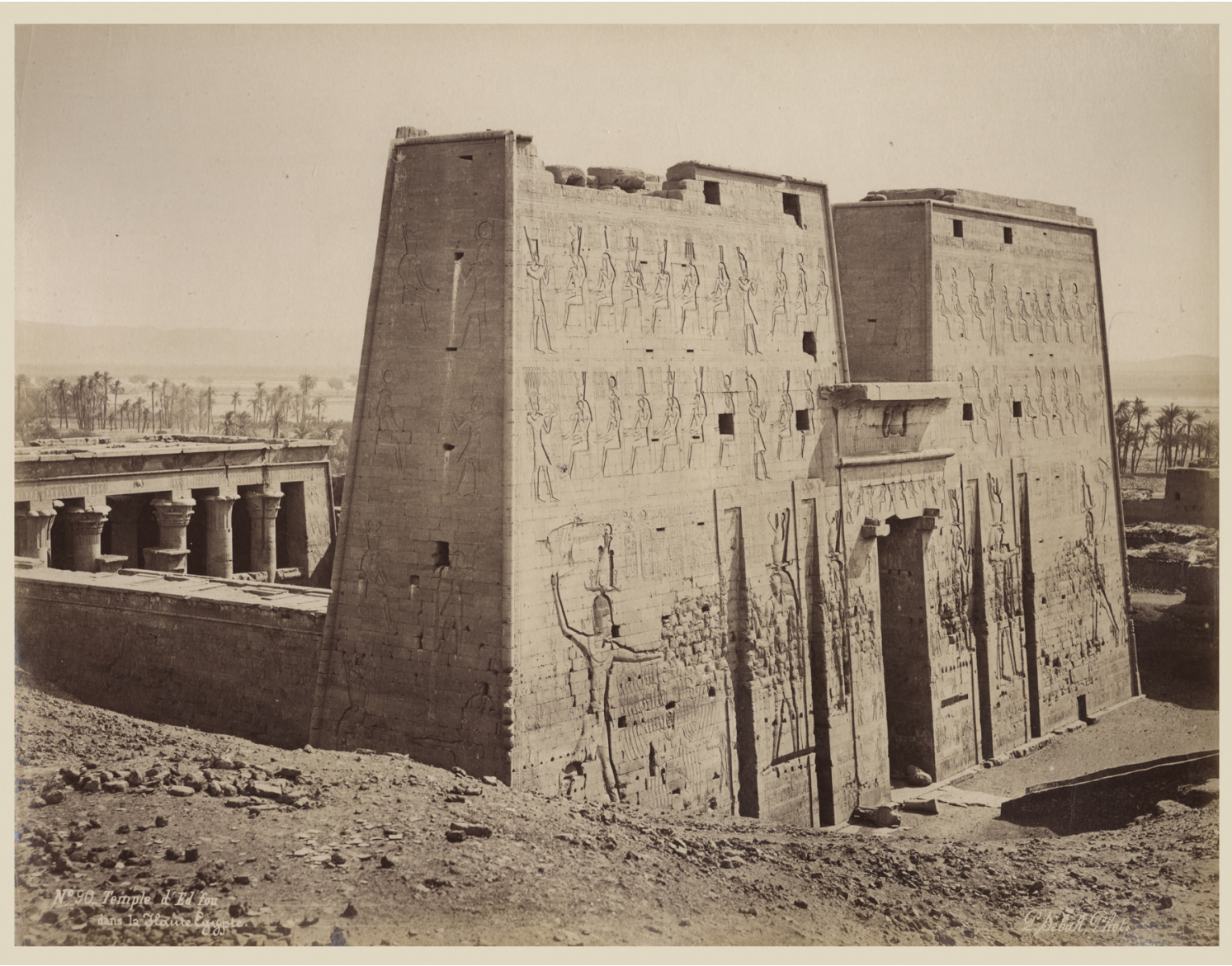

Figura 3:Templo de Horus Behdety en Edfu, pilono, fotografía de J.P. Sebah núm. 90, anterior a 1874 (Gl photograph 3381)

plios contactos e influencia en todo el territorio, cuyo papel predominante y estrecha reación con la corte alejandrina están bien ates-

vano, fueron los responsables de la elaboración de los protocolos onomásticos y de la dirección de las ceremonias de coronación de tiguados hasta el final de la dinastía ${ }^{59}$; no en los monarcas ptolemaicos ${ }^{60}$. Delegados de to-

${ }_{5}^{8}$ El interés de los Ptolomeos por la promoción de dicho culto -junto con los de Isis y Harpócrates, que completaron de Racotis en Alejandría, sede del santuario principal de la divinidad: a partir de entonces el culto tomaŕa una dimensión más popular, especialmente en la chóra y entre los habitantes de ascendencia griega y greco-egipcia, la cual culminaría en Época Romana con su difusión mediterránea; Hölbl 2001 [1994]: 99-101, 112, 170 y 310. Sobre Serapis, ver especialmente Vidman 1970; Stambaugh 1972; Hornbostel 1973; Takács 1995; Borgeaud y Volokhine 2ooo; Merkelbach 2001²; Sales 2005: 99-129; Pfeiffer 2008b.

59 Crawford 1980; Quaegebeur 1980; Reymond 1981; Thompson 1990; 20122: 99-143, esp. 128-136. Esta última obra constituye la referencia fundamental para la Menfis ptolemaica. 
dos los templos del país se reunieron regularmente en fechas señaladas, primero preferentemente en Alejandría o sus inmediaciones y más tarde en Menfis, para discutir cuestiones religiosas y negociar con el rey. Durante algunos de estos sínodos se promulgaron decretos, siguiendo la estructura y formato de los decretos honoríficos helenísticos, pero redactados tanto en griego como en egipcio (en escrituras jeroglífica y demótica) sobre estelas de tipo egipcio (fig. 4) ${ }^{61}$, las cuales se habrían erigi do en los santuarios más importantes del reino para asi publicitar las resoluciones adopta$\mathrm{das}^{62}$. Su contenido presenta a los Ptolomeos asumiendo las tradiciones y prácticas oficiales de la realeza egipcia, es decir, como monarcas piadosos cumpliendo con los deberes de faraón para con los dioses, publo y teritorio exipcios. Recogen aś a plias a ybazs, a ro egipcios. Recogen asi amplias a a menudo estereotipadas, pero también referen-

tre las que se cuentan multitud de beneficios

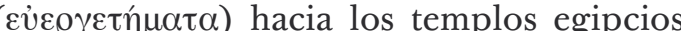
us cultos, incluyendo exenciones fiscales donaciones, in repatriacín de estatuas y objetos sagrados robalos por los persa ${ }^{63}$, la proforma . $^{64}$ la de fen has fantes de los en la de de rebclios encesigos extenos, la represión la justicia a el establecimiento del orden y la justicia a nivel interno. En agradecimiento por los actos de favor dispensados por los soberanos, la clase sacerdotal multiplica los honores divinos a sus señores extranjeros, bajo la forma de sacerdocios, festivales, estatuas de culto y coronas, así como otros muchos testimonios de lealtad al régimen.

Las disposiciones de los sínodos sacerdoLas fueron decinodos sacerdotales fueron decisva para el desarrollo del eos, es decir, para la introducción del culto al rey y su de Menfis = Piedra de Rosetta [196 a.C., British Museum, EA 24], OGIS I 90.28 = Urk. II, 183.5; ver Pfeiffer 2015: 111126, con extensa bibliografía), si bien existe una tradición literaria según la cual el mismo Alejandro Magno habría protagonizado esta ceremonia (Ps.Callisth., 1.34.2 (recensio $\alpha$ ); 1.34.2-3 (recensio $\beta$ )), lo que ha llevado a algunos autores a considerar que pudiera tratarse de una práctica habitual desde comienzos de la dinastía.

61 Como el Decreto de Canopo (Ptolomeo III, 238 a.C.), el Decreto de Rafa (Ptolomeo IV, 217 a.C.) y el ya mencionado Decreto de Menfis (Ptolomeo V, 196 a.C.). A la lista compilada por Clarysse 2ooob: 42-43, cabe añadir un nuevo decreto recientemente publicado por El-Masry, Altenmüller y Thissen 2012.

62 Huß 1994: 46-49; Clarysse 20oob; Hölbl 2001 [1994]: 105-111 y 162-169; Manning 2010: 97-102; Pfeiffer 2016: 13-16. 63 Winnicki 1994; Agut-Labordère 2017

64 Charron 1998. Los cultos a animales sagrados alcanzaron una posición central en la religión del periodo. Su promoción, junto con la restitución de imágenes y la restauración de santuarios, fue utilizada por parte de los soberanos Lágidas como herramienta propagandística en oposición a la "leyenda negra" que, con relación a los dos intervalos de ocupación persa precedentes, tanto las fuentes clásicas como la documentación oficial ptolemaica nos transmiten en forma de tópoi recurrentes (asesinato de animales sagrados y destrucción y expolio de recintos de culto). A pesar de que esta imagen desfavorable podria derivar de cierta actitud negativa generada en el seno de las elites indigenas durante los dos momentos de gobierno aquemenidia, y muy especialmente durante la Segunda Dominación Persa, periodo para el que la documentación conservada parece apuntar efectivamente hacia la paralización de los cultos ptolemaicos, los cuales la habrían alentado como arma ideológica y política para justificar y legitimar el nuevo orden establecido, despreciando el pasado inmediatamente anterior y señalando la continuidad de la función real de Argéadas y Ptolomeos con respecto de los últimos reyes nativos de la Dinastía XXX. La divulgación de la leyenda de Alejandro como hijo biológico de Nectanebo II (Ps.-Callisth., 1.1.1-14) estaría relacionada también con la voluntad de enfatizar dicha continuidad, convirtiéndola ficticiamente incluso en dinástica.

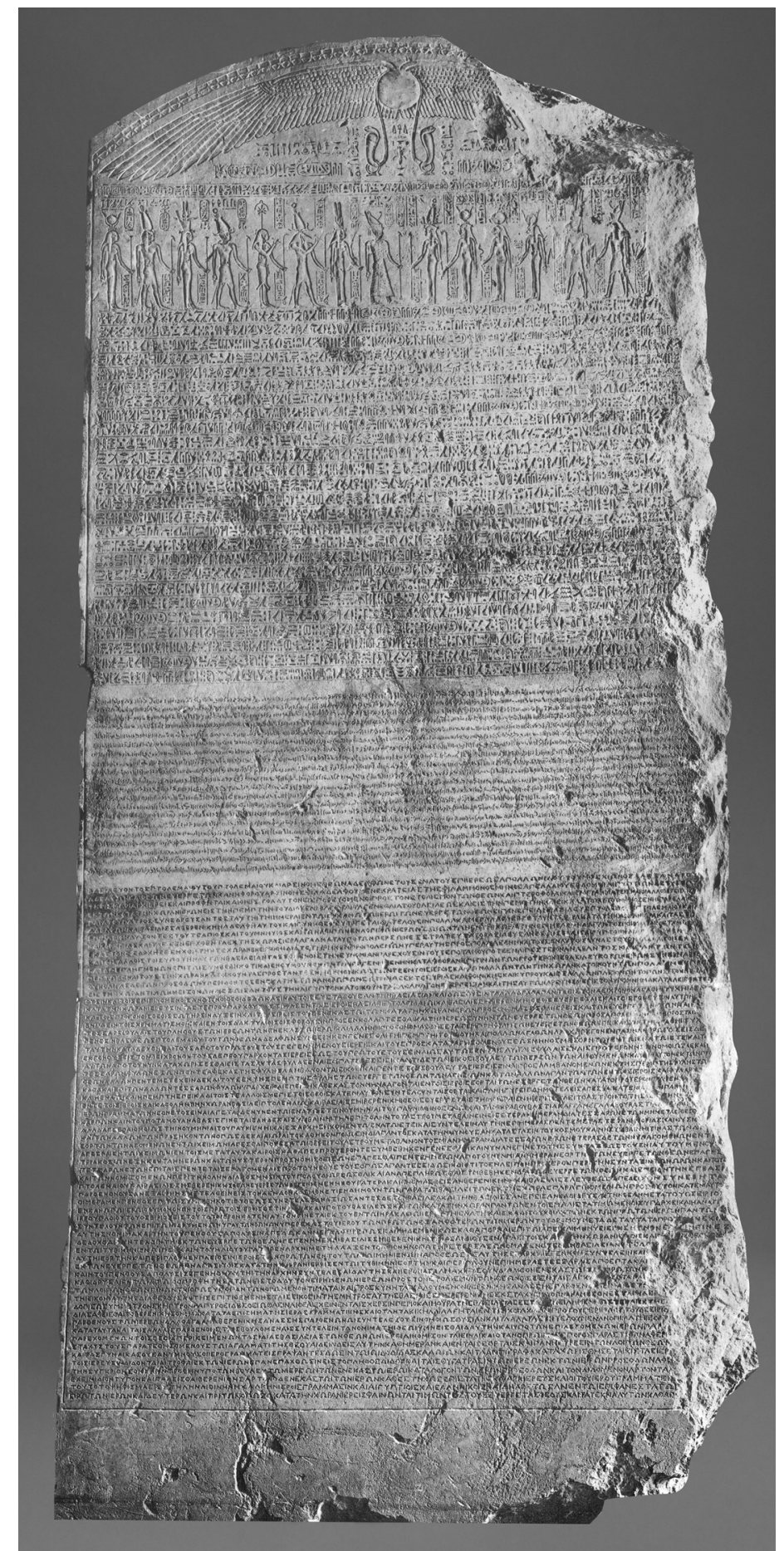
Figura 4: Decreto de Canopo, Museo Egipcio de El Cairo, CG 22186
(Kamal 1904-1905: II, pls. LXX-LXI combinadas).

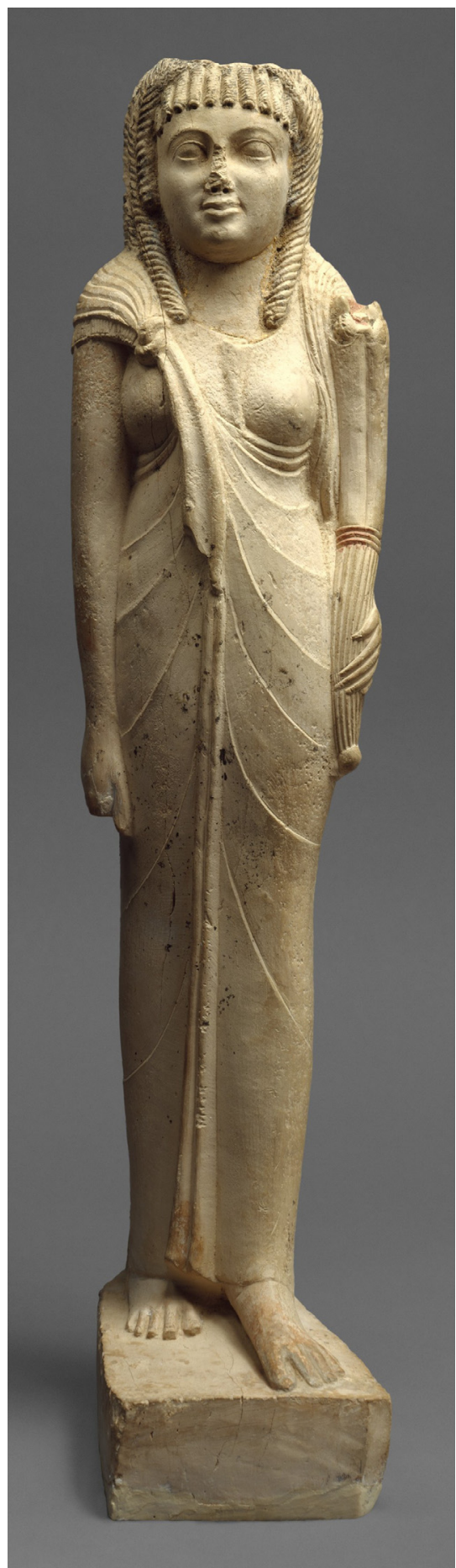

Figura 5: Estatuilla de Arsinoell,c. 150-100 a.C. he Metropolitan Museum of Art, Nueva York, Museum of Art/ www.metmuseum.org) 


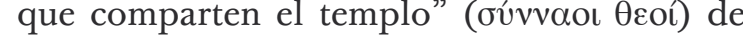
las divinidades locales ${ }^{65}$. El culto a la pareja ptolemaica, aunque ntes autóctonos en los cultos a los ancestros y a las estatuas reales ${ }^{66}$. Su primer testimonio o antecedente lo constituye la divinización de la reina Arsínoe II a su muerte en $270^{67}$ : de forma paralela al establecimiento de un culto de carácter griego, referido anteriormente, su imagen fue introducida también en los santuarios egipcios ${ }^{68}$ (fig. 5), junto con un impuesto específico so-

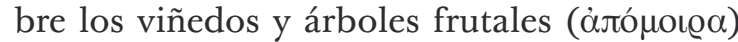
para sufragar las libaciones y ofrendas en honor de esta nueva diosa del panteón egipcio ${ }^{69}$ A partir de aquí el culto evolucionó, tomando como modelo jandrino, pero excluyendo a la figura de Alejandrine, pero excluyendo a la figura de Alejond por el dios principal del tenplo. En 238 , una

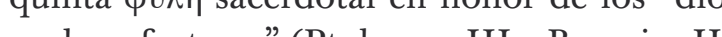
ses benefactores" (Ptolomeo III y Berenice II) fue añadida a las cuatro ya existentes, para servir al culto de la pareja real y de sus ancestro divinos ${ }^{70}$. Este culto fue insertado en el ritual de los templos, y las titulaturas oficiales de los sacerdotes pasaron a incluir los nombres de los soberanos divinizados tras el de la deidad principal $^{71}$.

\section{Economía y administración}

En contra de la visión tradicional que presenta al Egipto Lágida como un estado profundamente centralizado y eminentemen mercantilista, en el cual la corona habría ejercido un ferreo control sobre todos y cada uno de los aspectos administrativos y especialmente económicos del país del $\mathrm{Nilo}^{72}$, estudios más recientes dibujan un escenario mucho más complejo que obligan a matizar dicha apreciación, con significativas especificidades a nivel regional y variaciones a lo largo de los tres siglos de dominio ptolemaico, prueba de la mayor flexibilidad y adaptabilidad del sistema. Debido a las partapridades geograficas e hidrológicas de Egipto, los Ptolomeos se vieron forzados a mantener la estructura administrativa preexistente en gran medida inalterada, aunque lograron refinarla para aumentar su eficiencia, gracias a un equilibrio de tradición e innovación. A diferencia del pasado, los soberanos Lágidas introdujeron una administración civil, forjando así lo que ha sido definido como "un estado burocrático premoderno"73. La mayor preocupación del sistema administrativo ptolemaico fue, a todos los niveles, fiscal ${ }^{74}$, es decir, la obtención por parte de la corona de un flujo

65 Ver especialmente Pfeiffer 2008a; 2016: 16-17. También Hölbl 2001 [1994]: 88, 101-104, 109-111, 168 y 284.

66 Con algunas excepciones, en época faraónica el rey no recibió en vida un culto divino similar al de los dioses; fue

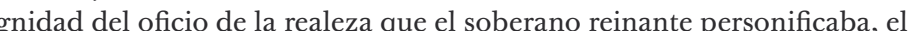

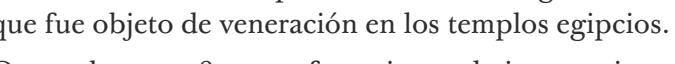

68 Estela de Mendes [c. 263-257 a.C., Museo Egipcio de El Cairo, CG 22181], 1. 13 = Urk. II, 41.11-42.1; ver Schäfer 2011: 239-273, esp. 249 y $261-267$

69 Clarysse y Vandorpe 1998.

o Decreto de Canopo [238 a.C., Museo Egipcio de El Cairo, CG 22187], OGIS I 56.23-33 = Urk. II 134.6-137.1; ver Pfeiffer $2015: 75-88$, con extensa bibliografía.

${ }_{71}$ Lanciers 1991; 1993.

72 Ésta es la visión predominante en Préaux 1939; Rostovtzeff 1941.

constante de ingresos para facilitar su competición militar política y cultural con sus rivales mediterráneos ${ }^{75}$. En consecuencia, la structura administrativa do tado giro en torno a la cap lach continua de impuestos procedentes de las distintas actividades ecomicas del reino y, muy especialmente, de la agricultura, base de la economía egipcia $^{76}$

El soberano ocupó la cúspide del gobierno, asistido por un reducido grupo de griegos y macedonios de su confianza, los llamados "amigos" ( $\phi i ́ \lambda o t)$ del rey, los cuales actuaron de forma colectiva como un consejo asesor del monarca y también desarrollaron a nivel individual importantes funciones en la administración y el ejército en calidad de altos funcionarios, generales, almirantes y embajador la cabeza de la jerarúa administava se enla cabeza de la jerach ad encontraban el secretario real para los asuntos diplomáticos (amotohoreapos), el secretario

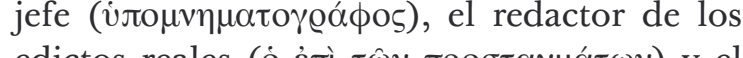

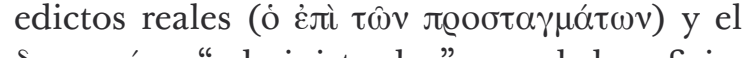

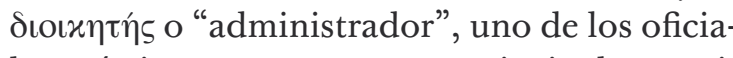
les más importantes y cuyo principal cometido fue la administración financiera del reino, como si de un ministro de economía y finanzas se tratara. Este último estuvo asistido por una armada de subordinados, incluyendo el "con-

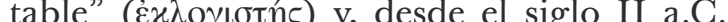

el responsable de la "cuenta especial" ('íı。 $\lambda \mathrm{O} \gamma \mathrm{O} \varsigma$ ), encargado de los recursos privados del

En cuanto a la organización administrativa del territorio egipcio, cabe señalar en primer lugar la existencia de tres ciudades grie-

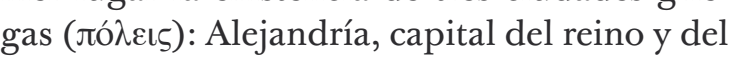
imperio, Naucratis, emporio fundado en el delta occidental en Época Saíta y que durante el último periodo de independencia indígena (Dinastía XXX) habría adquirido el estatus de polis $^{78}$, y Ptolemais Hermiou, ciudad fundada por Ptolomeo I en el sur del país como capital administrativa griega del Alto Egipto, reemplazando así a Tebas (Diospolis Magna) ${ }^{79}$. Estas tres ciudades contaron con órganos de grobierno autónomos y su propia tierra ( trx́) aunque sin escapar del control de la co(1) ( .

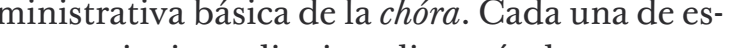
tas provincias o distritos disponía de su centro administrativo o capital ( los oficiales y de sus archivos, así como de distintas subdivisiones administrativas y financieras, que incluían distintos pueblos y aldeas. En tiempos de Ptolomeo II, el número de nomos se incrementó de 36 a 39; El Fayum fue uno de los nomos de nueva creación, el cual pasó a denominarse "nomo Arsinoíta" desde $c$.

Manning 2007: 442; 2010: esp. 55-72.

74 Lloyd 2000: 410

75 Rowlandson 2010: 238; Vandorpe 2010: 175

76 Manning 2007: 438 y 455; Kehoe 2010: 310. Ahora bien, cabe señalar que, con relación a la entrada de tributos a las arcas del estado, se priorizo estabilidad frente a cantidad, lo que explica los escasos esfuerzos que se dedicaron a mejorar la eficacia en la recaudación directa de impuestos a a incrementar la productividad de la tierra, si bien en

77 Lloyd 2000: 410-411; Hölbl 2001 [1994]: 58; Rowlandson 2010: 239.

78 Bresson 2005 .

79 Plaumann 1910; Abd-el-Ghani 2001.

8o Hölbl 2001 [1994]: 26-27. 
257 a.C. en honor a la esposa-hermana divinizada del soberano. El gobierno de cada nomo estuvo encabezado por dos oficiales, inicialmente de ascendencia griega, amb mente de ascendencin giega tados al disikets: el nomara (voukexis), responsable de la admistracion civil, y el ot@o-

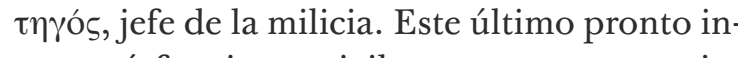
corporo funciones civiles a sus competencia militares, convirtiéndose en la principal figura administrativa de la provincia y relegando al primero a la categoría de empleado público menor con meras tareas financieras. Por debajo existió todo un cuerpo de subalternos, generalmente egipcios, entre los que podemos mencionar al oixóvos, encargado de las

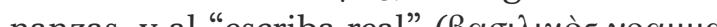

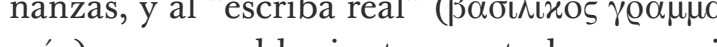
$\tau \varepsilon \cup 5)$, responsable, junto con toda una serie de asistentes en cada una de las subdivisione de la provincia, de la administración y el registro de la tierra y que con el tiempo acabaría reemplazando al oikonomos ${ }^{81}$. Durante todo el periodo la Tebaida constituyó una región administrativa diferenciada, incorporando varios nomos bajo la autoridad de un único strategós. Una de las consecuencias de la Gran Revuelta fue la creación del nuevo cargo de śmotó́ fue la creación del nuevo cargo de

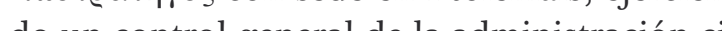
vil y miliar en to la choraj más tarde este vil y militar en toda la chora, más tarde este cargo se combinó habitualmente con el de strategós de la Tebaida. Asimismo, en el siglo I se documentan strategoí gobernando nomos individuales en la región, lo que apunta hacia una mayor homogeneización de la estructura administrativa de Egipto al final del Periodo Ptolemaico ${ }^{82}$.

Técnicamente, y a tenor de la terminologín

1 Falivene 1991; 2009: 522-530; Hölbl 2001 [1994]: 25 y 59

82 Hölbl 2001 [1994]: 157; Rowlandson 2010: 238 y 242

83 Thompson 1999a; 1999b; Hölbl 20o1 [1994]: 62-63; Manning 2003c: 99-125; 2007: 440-443 y 447-448; Kehoe 2010: 314 cuales tomaron nombres vinculados a la di- totalidad del territorio, pero su extensión y nastía, como por ejemplo Arsínoe, Filadelfia, Teadelfia o Filoteris ${ }^{84}$. El límite oriental del dela y proba de Ale y probableder de Alejandría también se expandieron con la puesta encultivo de nuevas tierras , yes posible que el potencial agricola de los oasis, y en especial de Dakhla, se comenzara ya a explota en estos momentos ${ }^{86}$, algo que posteriormente la administración romana sistematizaría. La creación de nuevos asentamientos no se limitó a El Fayum, sino que se documenta en otros puntos del país, muy especialmente en los nomos vecinos de Heracleópolis y Oxirrinco ${ }^{87}$ Nuevas fundaciones portuarias también se establecieron en la costa del Mar Rojo (Arsínoe/ Cleopatris/Klysma, Myos Hormos, Filoteras, Nechesia $\mathrm{Berenice}$, conectadas con distintas Nechis fu (Apollonopolis Magna), en el periodo que nos ocupa- mediante rutas terrestres a través del desierto oriental, las cuales las habrían mantenido abastecidas y habrían permitido también la llegada de bienes procedentes de Arabia, Etiopía e incluso de la India hasta Egipto $^{88}$

A pesar de que, como se ha señalado, el soberano habría reclamado la propiedad última de toda la tierra, un examen en profundidad del sistema de propiedad y tenencia de la misma en el Egipto ptolemaico nos presenta una realidad mucho más compleja ${ }^{89}$.

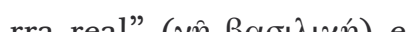
distribución exacta se desconoce. La puesta en explotación de nuevas áreas de cultivo tuvo como resultad la creación de tierra real, que explica que ́sta sea la cato que explica que pare indier que parece indicar que en algunas zomas delvalle del Nilo, y especialmente en la Tebaida, la proporción de tierra gestionada directamente por la corona habría sido considerablemente menor, debido fundamentalmente a la existencia de importantes templos con derechos antiguos sobre la tierra. La tierra bajo el control directo del monarca fue clave para los ingresos de la corona. Generalmente se trató de tierra altamente productiva, arrendada anualmente a "agricultores reales" ( $\beta \alpha \sigma \iota \lambda \iota x о \grave{~ \gamma \varepsilon \omega 0-}$ (oí) a cambio del pago de una renta en especie que teóricamente se habría ajustado en función de condiciones cabriantes, pero que en ción de condiciones canbiantes, pero que en de la de la mitad de la cosecha, y cuya tenencia se convirtió con el tiempo en estable, pudiendo pasar de padres a hijos. Sin embargo, gran parte de la tierra real no fue explotada según este sistema, sido cedida a otros para su traba-

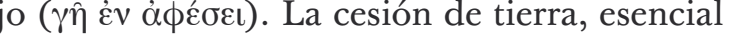
en los proyectos de extensión del área cultivable y en el mantenimiento y ampliación de los sistemas de irrigación, se presentó de dos formas distintas. Por un lado, se concedieron importantes lotes de tierra a oficiales de alto ran-

84 Davoli 1998; 2010: 350-255: Rowlandson 2002: 254-256; Mueller 2006: esp. 23-30, 60-64, 96-104 y 149-151: Clarysse 2007

86 Gill 2015; 2016

87 Rowlandson 2003: 256; Manning 2007: 441 y 447; 2010: 159

88 Mueller 2006: 151-157; Davoli 2010: 355-356

89 Para su estudio detallado, especialmente con relación a El Fayum y la Tebaida, ver Manning 2003c. Visiones sintéticas se ofrecen en Lloyd 2000: 411; Hölbl 2001 [1994]: 25 y 61-62; Manning 1999; 2007: 448-449 y 451-454; 2010: 159-163; Kehoe 2010: 314-319; Katary 2012: 16-20. La sinopsis que sigue a continuación se basa en todos ellos. 
pago o recompensa por el desempeño de determinados cargos de gobierno, los cuale revertían a manos de la corona al finalizar su ejercicio o a la muerte del titular. El mejor conocido es el dominio de 10.000 ar (c. 2.750 ha ) de Apporio, dioiketes de Ptolomeo II, en las in meo II, en las inmediaciones de Filadelfia en el nomo Arsinoíta ${ }^{90}$. Por otro lado, se asigna-

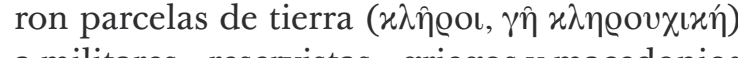
a militares -reservistas- griegos y macedonio

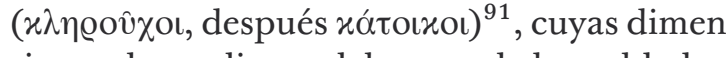
siones dependieron del rango de los soldados la caballería recibió 100 aruras, mientras que la infantería 20,25 o 30 . Este sistema, que se remonta a los inicios del dominio ptolemaico, fue una forma de recompensar a la clase militar y, a su vez, de reforzar el control del territorio e incrementar la presencia griega en el mismo. Originalmente las parcelas de los clerucos fueron revocables; su función fue proporcionar una base económica a una clase militar que podía ser llamada a filas para respaldar a la monarqún. Esto dominios fueron ge neralmente are Con portros. de la batalla de Rafa es 217 , soldados de de la batalla de Rafa en cendencia egipcia ( $\mu \alpha \chi \mu \alpha)$ también fueron incorporados al sistema, si bien recibieron lotes de tierra menores (5-10 aruras) y de peor calidad, lo que dificultó el empleo de mano de obra adicional. Con el tiempo las parcela pasaron a ser hereditarias, aunque sin poder ser enajenadas mediante venta. El asentamiento de clerucos se concentró en El Fayum también estuvo presente en otras regiones del país, especialmente en los nomos oxirrinquita y heracleopolitano y probablemente en

go El archivo de Zenón, agente de Apolonio y administrador del domino durante algún tiempo, ofrece valiosa información acerca de la economía, administración y población de El Fayum; ver Pestman 1981; Orrieux 1983: 1985. Clarysse y Vandorpe 1995. El archivo de Menches, escriba del pueblo ( Kerkeosiris, cercano a Tebtunis, constituye la segunda principal fuente de información sobre agricultura y tenencia de tierra en la provincia; ver Crawford 197; Lewis 1986: 104-123; Verhoogt 1998; 2005.

91 Uebel 1968; Fischer-Bovet 2014: 197-261. el delta. La situación fue bastante distinta en el sur del país, donde los templos y el mantenimiento de antiguos patrones de tenencia de tierra continuaron siendo importantes. Los dominios tradicionalmente administrados por los templos ( $\gamma \eta \hat{~ i \varepsilon ø o ́ ~}$ plotados privadamente por soldados, sacerdo, personal dependiente o bien arrendados individuales, persistieron, aunque pasaron a ser monitorizados por el estado. En la región se documenta también la tenencia y transferencia privada de tierra ( $\gamma \hat{\eta}$ i $\delta$ เó $\varkappa \tau \eta \tau o \zeta)$, sujeta al pago de un impuesto sobre la cosech inicion por el templo pero después recaudado directamente por la coroa, comparable en cuantía a las rentas derivadas del arrendamiento de tierra real. El estado, especialmente al final del periodo, frecuenlos arrendatarios en la tierra, viéndose obligado a recurrir a subvenciones, subastas públicas y reducción de impuestos para prevenir que la tierra se quedara sin cultivar. Aunque sistema de explotación de la tierra ptolemaco fue un éxito en la medida que consiguió lo que perseguía, a saber, la generación de sustanciales y continuos ingresos para la corona, los monarcas Lágidas fueron incapaces de sostener su constante desarrollo a lo largo del periodo, en gran medida porque el sistema de tenencia de tierra fracasó a la hora de proporcinar hayor libertad de acción e incen

Ptolomeo II fue el responsable de la introducción de importantes instituciones y reformas fiscales relacionadas con la explotación economica del reino. Si bien alguna de ellas podría haber empezado a forjarse en tiempos de Ptolomeo I, la documentación conservada nos presenta un sistema económico y adminisrivo plenamentec esarrollado y funcionando a la perfección bajo el reinado del segunintegrante de la dinastía ${ }^{22}$ Siendo la agricultura la principal actividad económica de Egipto, las rentas e impuestos derivados de la tenencia de tierra y de su producción agrícoa -fundamentalmente grano- constituyeron la mayor fuente de ingresos de la corona ${ }^{93}$. $\mathrm{Pa}$ ra su estimación, fue necesaria la ejecución de inspecciones anuales de tierras -después de la crecida del Nilo- y de cultivos - antes de la cosecha ${ }^{94}$. Los impuestos sobre cultivos de cereal siguieron siendo calculados y recaudados en especie, mientras que los impuestos sobre viñedos y árboles frutales lo furon en sobréti-

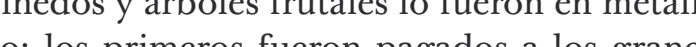
co, los pros anecos reales (0iouncor) y los segundos recaudados por los bancos (teaneba), ya fueran reles o privados, ambos con licencia estatal. La obligatoriedad de pagar ciertos impuestos en metálico y la difusion de los bancos por e territorio jugaron un papel decisivo en la progresiva monetización del pais ${ }^{95}$. Esencial para la difusión de la moneda fue también el establecimiento de los llamados "monopolios" ptolemaicos: los soberanos Lágidas tomaron nuevas medidas fiscales en la producción, manufactura y venta de determinados productos clave, como el lino la sal, el papiro y ciertos cultivos de aceite. A pesar de que la monar- de estas iniciativas comerciales, muchas fueron arrendadas y operadas por particulares, aunque bajo estricta supervisión y siguiendo las condiciones prestablecidas por la corona. El estado ptolemaico ofreció licitaciones cometivas y contratos de trabajo que fijaron a los trabajadores a un lugar detu lante su vigencia, frecuer deterninado du-

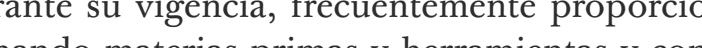
nando materias primas y herramientas y concediendo licencias para la comercialización venta del producto final, habitualmente a precios fijos. Más que el control estricto de la actividad económica, el objetivo principal de los "monopolios" ptolemaicos fue asegurar mano de obra y producir ingresos predecibles para la administración ${ }^{96}$. Los Ptolomeos oravaron también las actividades profesionales introdujeron un impuesto per cápita, el "imvuesto sobre la sal" (cỉń), documenta do tante todo el periodo. Fue gravado y cobrado en metálicoy aplicado tan to a hombescomo a mujer, aplicado tanto a hombres co(es, como por aunue algunos grupos sociame como por ejemplo maestros y atletas, este proporcionó importantes ingresos a la corona debido a su anplia aplicación. Pronto se combinó con el óboo (oßoßós), otro impuesto de capitación, eminentemente simbólico, aplicado sólo a hombres y del que estuvieron exentos determinados orupos étnicos, como los helenos y los persas. La base para la percepción de impuestos sobre personas y ganado fue el censo ${ }^{97}$. La

92 Thompson 2008

93 Algunos de los detalles del sistema tributario ptolemaico todavía hoy escapan a nuestra comprensión, debido a su en Manning 2007: 455-458

94 Manning 2003c: 146-156; 2007: 449-456; 2010: 160.

5 Manning 2007: 444-446, 450 y 455-457; 2010: 130-138, 156 y 158; von Reden 200

96 Manning 2007: 445

97 Manning 2007: 449 y 458; 2010: 142-144; Thompson 1997; Clarysse y Thompson 2006. 
recaudación de impuestos fue una tarea com- de impuestos, la burocratización del estado y pleja, la cual involucró evidentemente al sector el establecimiento de una administración civil, público pero también al privado, puesto que acompañados de la implantación de los granefue habitual arrendar impuestos a particulares ros y bancos reales por todo el territorio para

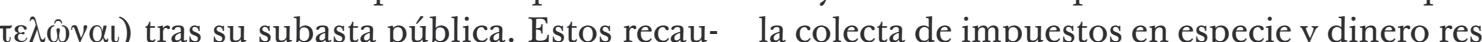
dadores frecuentemente operaron bajo el res- pectivamente, junto con el control monopopaldo de asociaciones, con importantes can- lístico sobre la producción y comercializació tidades de capital a su disposición. Tenían la de determinados bienes, comportaron la proobligación de entregar al monarca las canti- gresiva pérdida de su papel preponderant dades estipuladas en los contratos, beneficián- en la dirección de la vida económica del pais dose del superávit que el recaudo generara. La $\quad \mathrm{y}$, a su vez, su paulatina incorporacion al estarecaudación privada de tributos fue un meca- do ptolemaico. A pesar de que los decretos renismo más de la administración ptolemaica pa- ales evidencian la reducción o total exención . En el Periodo Ptolemaico los templos con- incluso certifican el mantenimiento de ciertos tinuaron siendo importantes organizaciones de sus privilegios, lo cierto es que la adminiseconómicas ${ }^{99}$. Como se ha señalado anterior- tración ptolemaica pasó a monitorizar de formente, su principal fuente de ingresos fue la ma escrupulosa las finanzas de los santuarios; tierra bajo su gestión. Ahora bien, además de prueba de ello es la aparición de nuevos car-

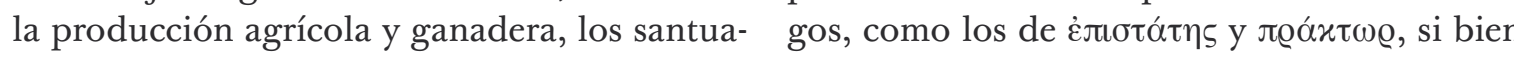
rios egipcios también albergaron toda una se- pronto serían frecuentemente ocupados por rie de actividades industriales, como la fa- personal del templo. Desde finales del siglo II bricación de aceite, papiro y tejidos, especial- a.C. los santuarios recibieron una retribución

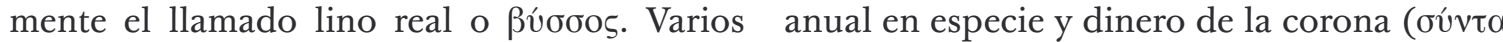
servicios religiosos les reportaron significa- $\xi 15$ ) la cual ha sido frecuentemente interpretivas ganancias adicionales, como por ejem- tada como una medida compensatoria por plo la consta or ola industria de la cación, entierro y manteniniento del culto fu- prerrogativas tradicionales, pervivió, aunque nerario de particulares, así como también la su importancia se redujo gradualmente a cau gestión de los populares cultos a animales sa- sa de la progresiva implantación del griego en grados -elaboración y sepelio de momias de la administración y el sistema legal a expenanimales votivas como ofrendas a divinidades sas del demótico, y especialmente debido al redeterminadas-. Aunque los santuarios, espe- querimiento desde 146 de que todos los contracialmente en la etapa inicial, continuaron te- tos demóticos, para garantizar su validez legal, niendo un papel destacado en la recaudación

98 Hölbl 2001 [1994]: 62; Manning 2007: 450 y 452; 2010: 152-157. Las Revenue Lawes, un conjunto de decretos oficiales reunidos en dos rollos de papiro de mediados del s. III a.C., constituyen una importante fuente de información acerca de la fiscalidad ptolemaica, incluyendo los monopolios reales y la recaudación privada de impuestos; ver Bingen 2007 [1978]

99 Quaegebeur 1979; Johnson 1986; Clarysse 2010: 279-289. ran en las notarías oficiales griegas ( $\alpha \gamma o \varrho \alpha v o-$ de velar por el desarrollo adecuado de los pro$\mu \varepsilon \hat{\imath} \alpha / \dot{\alpha} \gamma o \varrho \alpha v o \mu ́(\alpha)$, implantadas en las capitale de los nomos desde finales del siglo III 100

El sistema legal ptolemaico coordinó la le- tre egipcios y griegos; más tarde estos casos gislación tradicional egipia junto con la de fueron dir y

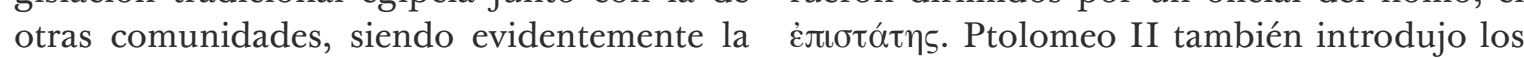

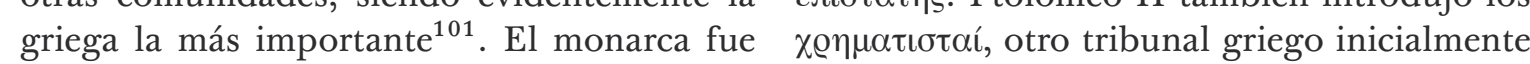
la máxima autoridad judicial del reino, pero itinerante que se enviaba al territorio para limitó su actuación a los asuntos legales de im- juzgar casos concretos y que posteriormente portancia estatal; a pesar de que las peticiones quedó establecido de forma permanente en las para iniciar una demanda se dirigían formal- localidades más importantes de los nomos, remente al soberano, éstas fueron habitualmente levando a partir del siglo II a los dıжaбtíoto

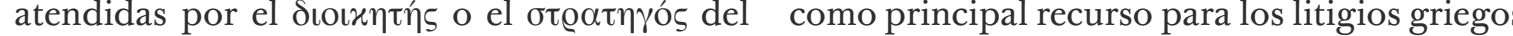
nomo. Todo parece indicar que, a comienzos y disminuyendo incluso la importancia de los del periodo, las polis griegas del país gozaron $\lambda \alpha o x o i ́ \tau \alpha$, puesto que también la población de sus propios sistemas legales. Ptolomeo II egipcia acabó prefiriéndolos frente a las cor-

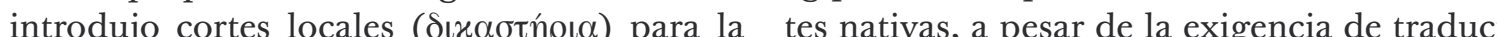
población griega asent poblión griego para

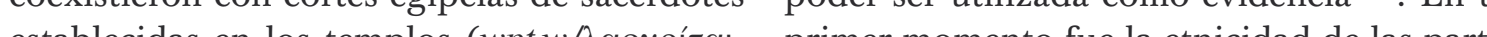
establecicas en "juect los Jueces de la gente (nativa)"), las cuales se la que resolví si un caso era conpetencia de rigieron segun las leyes ancestrales del pais, una corte griega o bien egipcia, pero a partir codificadas durante el reinado de Darío I (Di- de 118, de acuerdo con una de las cláusulas de nastía XXVII) y sancionadas por Ptolomeo un decreto real (pTebt. I 5.207-220), la elección II como "la(s) ley(es) de la tierra" (ó vómos/oi se efectuó en función de la lengua emplead

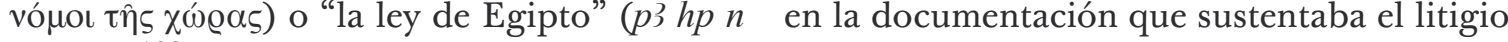
$\operatorname{Kmy}(. t))^{102}$, aunque su marco de actuación se Además de estos tribunales de justicia, tamlimitó eminentemente a cuestiones civiles. Am- bién los altos funcionarios del nomo, como el bos tribunales estuvieron controlados por el nomarca, el strategós, el epistates y ciertos ofistrategós del nomo, quien decidía cuál de ellos ciales financieros, contaron con capacidad jutenía jurisdicción sobre cada caso, y también dicial para arbitrar ciertas disputas. Las cortes supervisados por un representante real (el griegas y los funcionas que actuaron como

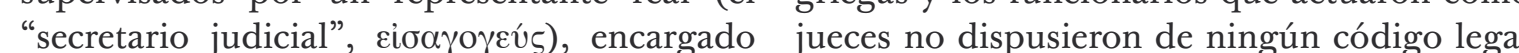

100 Pestman 1985; Rowlandson 2003: 261; 2010: 245; Yiftach-Firanko 2009; Manning 2010: 193; Vierros 2012.

101 Para el estudio del sistema legal del Egipto Lágida, ver especialmente Seidl 1962²; Wolff 1970²; 1978; 2002; [Mélèze]Modrzejewski 1975; 1995; Lenger 19802; 1990; Allam 1991: 119-127; 2008; Manning 2003a; 2010: 165-201; Lippert 2008: 85-190; Keenan, Manning y Yiftach-Firanko 2014. La síntesis que aquí se presenta sigue fundamentalmente a Rowlandson 2010: 243-245; Lippert 2012a: 5; 2012b: 8-10.

2017. Traducidas después al griego, estas leyes nativas seguirían vigentes hasta la segunda mitad del siglo II d.C.

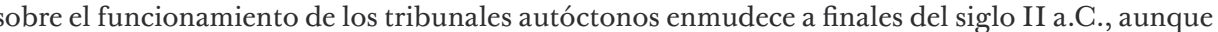
es posible que todavía siguieran actuando a principios del Periodo Romano. 

zas" cenerales (Draygónuora) y "reglamentos" específicos (mootcipura) recogidos en los" nizados presentes en el Egipto Lámida fuernizados presentes en el Egipto Lágida fueron completo, por lo que tuvieron que basar sus sentencias fundamentalmente en las "ordenancretos $y$ edictos reales, los cules tenan fuer-

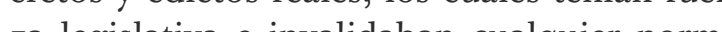
za legislativa e invalidaban culquier norna precedente, incluyendo las egipcias, asi como en las leyes de una ciudad determinada (תo $\lambda_{-}$ tıxoì vómol -se discute si esta expresión haría referencia a las polis de origen de los litigante en la Grecia continental o bien a alguna de la tres polis egipcias-) o, llegado el caso, en su propio sentido de justicia.

\section{4. | Sociedad}

La sociedad del Egipto ptolemaico fue una sociedad multicultural y multilingüe que atrajo inmigrantes de todo el Mediterráneo orienjo inmigrantes de todo el Mediterraneo orien-
tal $^{104}$. Evidentemente, los egipcios constituyeron el grupo étnico mayoritario, seguituyeron el grupo étnico mayoritario, seguidos por los griegos y macedonios, los cuales se asentaron en el país del Nilo desde los momen tos iniciales de la conquista y especialmente a lo largo del siglo III a.C. La tercera etnia en importancia fue la judía: desde Palestina, que formó parte del Imperio ptolemaico durante casi un siglo, emigró un destacado número de población hebrea, la cual se concentró especialmente en la ciudad de Alejandría y acabó helenizándose $e^{105}$ Otros grupos étnico hab los tracios, jonios y carios, estos dos ultimos asentados en el teritonio, y expecialnente en También se documentan poblaciones origi-

narias de distintas posesiones exteriores ptolemaicas, como fenicios, samarios e idumeos, as como sirios, nabateos, árabes e incluso persas. En consecuencia, la sociedad del Egipto de los Ptolomeos puede ser definida como una socieremos fundamenta interacción que se produjo ente las dos etias principar ese procujo entre las dos etnias pripa y la élite greco-macedonia, junto con los procesos de helenización y aculturación de la primera, pero sin olvidar la influencia que la cultura egipcia ejerció también en la segunda. Cabe señalar de antemano que dicha interacción fue más activa en las ciudades y zonas con mayor concentración helena. La población griega nunca llegó a representar más del $10 \%$ ritori , aunque su distribución por el tegos fueron incyoratios; Menfis tabien bergé una fuerte presencia griega y es poin alque cencen heleno

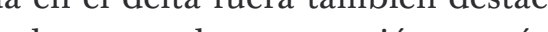
, si bien la escasa documentación que éste proporcionado no permite corroborarlo. Después de la capital, El Fayum constituyó e segundo gran foco de atracción de inmigrantes griegos, fundamentalmente soldados que se asentaron como clerucos; a mediados del siglo III la población helena del nomo Arsinoíta alcanzó el $30 \%$ de un total de aproximadamente 85.000 habitantes ${ }^{109}$ Asimismo, a desen comienzos del siglo III se atestigua presencia griega en la Tebaida fundamentalmente en forna en la Tebicios filtares tablecidas en puntos estateicos, como por ejemplo Elefantina, Coptos y Edfu -enclaves

104 Vandorpe 2010: 171.

105 Hölbl 2001 [1994]: 189-191.

106 Thompson 2009: 404-405; 2012²: 77-78 y 87-90.

107 Goudriaan 1988; La da 2002; Thompson 2009: 399-406.

108 Manning 2007: 441; 2010: 138; Thompson 2009: 401 (c. 15\%); Vandorpe 2010: 176 (5-10\%). 107 , dibien aquí nos concentrdel tota $1^{108}$, lingó a representar más del $10 \%$ situados en los extremos de rutas comerciales que conectaban el valle del Nilo con el sur y el Mar Rojo-, las cuales incrementarín en puesta a los distinto as siomientos interno lena en la regín fusencia de población helena en la región fue porcentualmente muy poco significativa, debido en gran medida a la lo que explica, por ejemplo, que Tebas se man tuviera abrumadoramente egipcia desde un punto de vista poblacional a lo largo de todo el periodo ${ }^{111}$. La mayoría de autores asume un incremento general de población en el Periodo Ptolemaico, causado en gran parte por la llegada de inmigración a los nuevos centos llegada se estima que, en el siclo I a.C.,

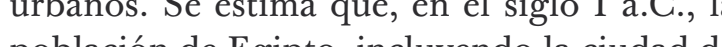
población de Egipto, incluyendo la ciudad de nes de habitantes. Alejandía concentró una población de aproximadamente 200.000 habitantes a mediados del siglo III, incremen tándose probablemente hasta los $500.000 \mathrm{a}$ principios del Periodo Romano; Menfis albergó una población de 50.000-60.000 almas; de acuerdo con Estrabón (17.1.42), Ptolemais fue la ciudad más importante de la Tebaida, comparable en tamaño a Menfis; la población de Tebas habría rondado los 50.000 habitantes ${ }^{112}$

La interacción entre egipcios y greco-maceLonios se produo en ámbios yuy divesos, pero fue en el ejército y especialmente la administración donde se dejó sentir con más número a lo largo de A pesar de ello, la pren. escasa difusión de la tenencia militar de tierra, Alejandria, se situaría entre los 3,5 y 4,5 millo- fuerza, y ya desde inicios del periodo. La documentación egipcia nos informa de la existencia de figuras eavas infuyentes tanto bajo el rein de Alejan pertenien a la jera pero pero murespecialmente vinculados a la esfera (Detanebo, emparentado con Nectanebo I (Dinastía terior, los Ptolomeos introdujeron una adm nistración civil por todo el territorio; se trató de un sistema gestionado a todos los niveles por escrito, o en otras palabras, con la alfabetización como columna vertebral ${ }^{114}$ Aunque suficiente capaz de operar en altos, tanto a niver esal con provina fuero fure me la administración local permaneció en manos de sacerdotes y escribas profesionales egipcios, es decir, bajo el control de la clase social culta tradicional, formada en los templos y funcionando como anteriormente en demótico. La burocracia inicial fue, pues, clara distinción entre "funciones" griegas egipcias dependiendo de su posición en la je rarquí administrava ${ }^{115}$. Sin esión en la jejándose: parte del cuerpo nativo de oficiales te $\mathrm{XXX})^{113}$. Como hemos visto en la sección anel griego se convirtió en la lengua principal de la nueva administrán la falta de persol de des un buen comieno, a incorpora a personal indigena Evidentem a incorporar a perouna burocracia bilingüe, aunque con una tiempo esta mata separacion fue desdibu-

109 Thompson 2009: 401. Ver también Manning 2003c: 107-110 (población total de $c$. 100.000 habitantes y referencia a distintas oleadas de asentamiento de militares); 2007: 442; 2010: 139-140 (85.000-100. 000 habitantes); Clarysse

110 Manning 2003c: 33-34, 96-97 y 169: Pollard 2010: 450-451: Rowlandson 2010: 258.

111 Rowlandson 2010: 258 .

112 Manning 2003c: 440-442; 2010: 138-140; Rowlandson 2003: 253-254; Kehoe 2010: 312.

113 Lloyd 2000: 411-412; 2002; Hölbl 2001 [1994]: 27.

114 Thompson 1992a; 1992b; 1994; Manning 2010: 14 
estatales aprendió y pasó a operar también en griego, lo que les permitió escalar peldaños en el escalán administrativo; algunos tomaron nombres griegos llegaron a alcanzar el cstatus de "heleno", repón a alcanzar el estajus 116 " , iportándoles cietas ventajas fiscales . A partir del sigho II varias familias egipcias bilingües pasaron a dingir las notarías oficiales griegas en distintas localidades, como por ejemplo en Gebelein (Pathyris) ${ }^{117}$ es probable que algunas de ellas incluso se hubieran hecho cargo de bancos y graneros re$\operatorname{ales}^{118}$. Desde tiempos de Ptolomeo VIII en adelante encontramos a nativos ejerciendo los más altos cargos de la administración ${ }^{119}$, in-

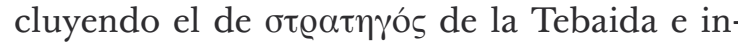

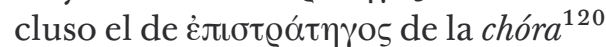

La sociedad del Egipto ptolemaico fue una sociedad estratificada, con clases o grupos sociales diferenciados tanto por la etnicidud de sus integrance clome, muy especilmente, por su ocupacín ${ }^{121}$. Por una parte la poblacion gucco-macedonia ocupo los puestos más elegreo-nacedonia ocupó los puestos más elevados en la escala social, con la elite dirigiendo la administración del país situada en la cúspide y la clase militar asentada en el territorio, ya fuera en guarniciones o como colonos, por debajo ${ }^{122}$. Por otra parte, el elemento indígena se mantuvo organizado según patrones tradicionales, con el estamento sacerdotal, el cual durante milenios había constituido el eje social, económico y cultural del territorio,

cabeza ${ }^{123}$, seguido por la clase de escribas responsables de la gestión cotidiana del sistema administrativo a nivel local y hasta cierto punto también provincial. Por debajo en la jerarqú́ qua socintester plos, pero otros establecidos los centros plos, pero otros establecidos en los centros urbanos, y, seguidamente, la milicia egipcia ( $\mu$ $\chi(\mu o t)$, con funciones policiales en el territorio o bien ejerciendo de soldados en el ejército despues de su contribución en el desenlace de la Cuarta Guerra Siria, también como receptores de parcelas de tierra y, en consecuencia, asentados en el campo. La base estuvo ocupada por la gran masa de campesinos egipcios ligados a la producción agrícola y ganadera y encargados del mantenimiento de los sistemas de irrigación, tareas que desarrollaron como simples peones o bien en calidad de arrese la corona, del templo o en randes fincas. Si bien algunos de ellos cier. Si bien algunos de ellos ciermayoría operó en un estricto es que la gran estricto nivel de subsistencion fiscal y económica llegó en ocasiones a convertir su situación en insostenible, empujandoles a abandonar

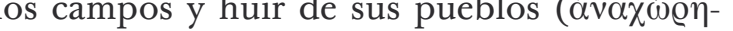
oا५) y a optar por el bandidaje, la búsqueda de refugio en ciudades y templos (derecho de asilo o "detención (religiosa)", жатохй) o incluso a sumarse a las revueltas contra el o iobierno

115 Manning 2010: 147.

116 Thompson 2001; Clarysse y Thompson 2006: II, 138-147; Falivene 2009: 524-525; Manning 2010: 88

117 Manning 2003c: 187; 2010: 192-193; Vierros 2012.

118 Vandorpe y Clarysse 2008; Clarysse 2010: 284

119 Hölbl 2001 [1994]: 198 y 257

20 Johnson 1986: 81-82; Lloyd 2000: 419; Hölbl 2001 [1994]: 198 (con referencia al egipcio Paos, quien ocupó ambos puestos); Rowlandson 2010: 242.

21 Para una aproximación a la composición social del Egipto Lágida, ver Manning 2003a: 832-833; Lloyd 2000: 412-413 y 417-418; Clarysse y Thompson 2006; Cruz-Uribe 2010: 494-495

122 Con relación a esta segunda, ver especialmente Pollard 2010. 450-452; Fischer-Bovet 2014.

123 No se trataría de un grupo homogéneo, sino a su vez jerarquizado; ver Clarysse 2010: 287-289. central $^{124}$. Los gobernantes ptolemaicos intentaron poner fin a este descontento general

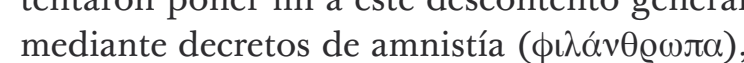
habitualmente promulgados tras episodios de rebelión o guerra civil, en los que se perdonarebelión o guerra civil, en los que se perdona-
ban crímenes y reducían o condonaban deuban crímenes y reducían o condonaban deu-
das $^{125}$. La esclavitud existió, aunque no se emdas $^{125}$. La esclavitud existió, aunque no se em-
pleó en la agricultura; los hogares griegos contaron con esclavos y éstos también fueron utilizados, junto con prisioneros, como mano de obra para la explotación minera del desierto oriental $^{126}$.

La dicotomía étnica inicial entre griegos y egipcios con el tiempo se tornó borrosa, afectando en cierta medida también a la diferenciación ocupacional. Dos fueron los factores principales que contribuyeron a la progresiva fusión de ambas culturas: los matrimonio mixtos y la movilidad social ${ }^{127}$. Muchos inmigrantes griegos que se instalaron en el territorio se casaron con nativas, en parte debido a la escasez de mujeres de origen heleno ${ }^{128}$ A través de la movilidad social, la élite cia fue capaz de cia fue capaz de accerado en el ejército y la adninistración. Como consecuencia, aquellos nativos que de algún modo adoptaron la cultura helena asumieron un identidad ya fuera griega o bien egipcia en función del contexto social en el que se movieran, es decir, dependiendo de si se encontraban en un ambiente laboral/oficial o bien familiar. En la documentación del siglo II en adelante ya no es posible identificar a una persona como

griega o egipcia en base a su nombre o etnicidad: muchos habitantes asumieron un nombre doble -uno griego y el otro egipcio-; puesto que además pudieron recibir una nueva designación étnica como resultado de una promoción, éstas perdieron su significado geográfico original y pasaron fundamentalmente a denotar estatus ocupacional y legal ${ }^{129}$. Una de ellas fue la ya referida categoría de "heleno", a la cual muchos nativos accedieron gracias a su participación en la sociedad y burocracia griega. La presencia de población de origen grecomacedonio asentada en el territorio, los marimonios mixtos, la d trime la elite indigena y su ascenso en el escalafón administrativo fueron todos ellos elemento que propiciaron la interacción cultural entre las dos etnias mayoritarias del reino, hasta punto que en el Periodo Ptolemaico tardío, a pesar de que las culturas griega y egipcia permanecieron en esencia separadas, muchos individuos fueron "biculturales" a efectos prácticos ${ }^{130}$ Ahora bien, en esta interación la ura griega ocupó siempre una posición predominante, por lo que, más que un intercbio equitavo ente ambas culuras, lo que en realid se doce anbas culturas, lo que helenización de las élites egipcias, o dicho de otro modo, su paulatina aculturación o atraccion hacia la cultura de la clase gobernante. Una de las formas en las que la helenización se expresó fue la lengua ${ }^{131}$. El oriego se impuso como lengua del poder a nivel escrito

124 Lloyd 200o: 419-420; Hölbl 2001 [1994]: 153-157 y 182-183; Veïsse 2004: 144-145.

125 Hölbl 2001 [1994]: 157, 184, 195 y 201-202; Manning 2003a: 822; Veisse 2004: 171-183 y 213-220; Rowlandson 2010: 242-243.

126 Clarysse y Thompson 2006: II, 262-267; Manning 2007: 451; Thompson 2009: 403 .

127 Vandorpe 2010: 172-173.

128 Thompson 2009: 403

129 Clarysse $1985 ;$ La' da

130 Rowlandson 2003: 262. 
como tal, fue progresivamente ganando terreno a expensas del demótico en los sistemas administrativo y legal. En el Periodo Ptolemaico inicial, ambos sistemas se desarrollaron ampliamente en demótico; sin embargo, las élite egipcias gradualmente incorporaron el griego egipcias gradualmente incorporaron el griego debido a las ventajas que, desde un punto de vista social, ello comportaba, convirtiendose
en funcionalmente bilingües. Muchos archien funcionalmente bilingues. Muchos archvos bilingües han sobrevivido hasta nuestro días; los archivos estrictamente en demótico se circunscriben a la fase inicial del periodo y a sur del país, principalmente Tebas; después de la supresión de la Gran Revuelta en la región, éstos pasaron a ser también bilingües. La introducción en 146 de la obligatoriedad de registrar los contratos en las notarías oficiales griegas para asegurar su validez supuso el comienzo del declive del uso del demótico en la donzodel declive del uso del demórico en la docudo torion conte de do totalmente desbancado por el griego a finales del siglo I d.C. . El demótico continuaría empleandose para registrar recibos de im puestos, como minimo en el area tebana, hasta el siglo II d.C., y en la documentación administrativa de los templos y la literatura hast el III ${ }^{133}$. Ahora bien, siendo la cultura egipcia la mayoritaria, la interacción entre ambas etnias no fue un proceso unidireccional: los griegos adoptaron los rituales egipcios de la reale$\mathrm{za}$, las divinidades locales -llegando en ocasiones a servir como sacerdotes en los templos locales-, y hasta cierto punto también alounas de las manifestaciones ásticas, concepnas de las lanifestacion pá ciones de un adopion, lo que denota la exis de su tierra de adopción, lo que denota la existencia de una cierta "egiptización" de la población helena del Egipto ptolemaico ${ }^{134}$. Tampoco lo griegos lograron escapar del poderoso hechizo ra de los faraones.

Bibliografía

Abd El Gawad, H.

2012 "Tell me your name and I can tell you how your kingship was: The royal names of the Abd El Gawad, N Andrews. M. CorreasAmador, V. Tamorri y J. Taylor (eds.): Current Research in Eoyptology 2011: Proceedings of the Troelfth Annual Symposium which took place at Durham University, United Kingdom, March 2011, Oxford: 1-14

ABD-EL-GHANI, M.

The Role of Ptolemais in Upper Egypt outside its Frontiers", en: I. Andorlini, G. Bastianini, M. Manfrediy G. Menci (eds.): Atti del XXII Congresso Internazionale di Papirologia, Firenze, 23-29 agosto 1998, Firenze: vol. 1, 17-33.

\section{AGUT-LABORDÈre, D.}

"Persianism through Persianization: The Case of Ptolemaic Egypt", en: R. Strootman y M.J. Versluys (eds.): Persianism in

Agut-LABordère, D; GorRe, G.

"De l'autonomie à l'intégration. Les temples égyptiens face à la couronne des Saittes (VIe-III' siècle av. J.-C.)", Topoi 19: 17-55

AlLAM, S.

"Egyptian Law Courts in Pharaonic an Hellenistic Times", FEA 77: 109-127.
131 Cruz-Uribe 2010: 492-493

132 Depauw 2003.

33 Manning 2003c: 171-177, 186 y 238; Thompson 2009: 407-409. El último contrato demótico del que se tiene constancia está fechado en 175/176 d.C.

134 Clarysse 1992; 2010: 184; Manning 2003c: 192; Thompson 2009: 402-403; Vandorpe 2010: 171-172.

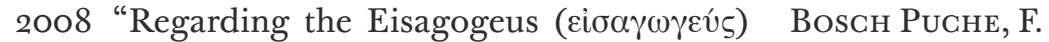

at Ptolemaic Law Courts", $f E g H$ 1: 1-19.

2012 "Alejandro Magno y los cultos a animales sagrados en Egipto", Aula Orientalis 30 : $243-277$

2003 "Alexander and Siwah", AncW 34: 117.

2013 The Egyptian Royal Titulary of Alexander the Great, I: Horus, Two Ladies, Golden Horus, and Throne Names", $7 E A$ 99: 131-154.

1999 Temples of the Last Pharaohs. New York.

Asнтол, S.-A.

oo8 Cleopatra and Egypt (Blackwell Ancient Lives). Malden. touches, Final Remarks, and Appendix", fEA 100: 89-109.

BOWMAN, A.K.

Bagnall, R.S.; Rathbone, D.W. (EDs.)

2004 Egypt: From Alexander to the Copts. An Ar chaeological and Historical Guide. London.

BALLET, P.

1999 La Vie quotidienne à Alexandrie, 331-30 avan J.-C. Paris.

Bielman SÁnchez, A.; Lenzo, G.

2015 Inventer le pouvoir féminin: Cléopâtre I Cléopâtre II, reines d'Égypte au II ${ }^{e}$ s. av. F.C.C. (Echo 12). Bern.

BINGEN, J.

007 "The Revenue Laws Papyrus: Greek Tradition and Hellenistic Adaptation", en: J. Bingen: Hellenistic Egypt: Monarchy, Sociey, Economy, Culture, Edinburgh: 157-188 (ed. orig. Opladen: 1978)

BLÖвAUM, A.I.

2006 „Denn ich bin ein König, der die Maa liebt". Herrscherlegitimation im spätzeitlichen Ägypten. Eine vergleichende Untersuchung der Phraseologie in den offiziellen Königsinschriften vom Beginn der 25. Dynastie bis zum Ende der makedonischen Herrschaft (AegMonast ). Aachen

Borgeaud, P.; Volokhine, Y.

"La formation de la légende de Sarapi une approche transculturelle", $A R G$ 2: 37
1986 Egypt After the Pharaohs, 332 BC-AD 622: From Alexander to the Arab Conquest. London.

BRESSON, A

2005 "Naucratis: de l'emporion à la cité", Topoi 12-13: 133-155.

Carney, E.D.

2013 Arsinoë of Egypt and Macedon: A Royal Life (Women in Antiquity). Oxford.

Charron, A.

1998 "Les Ptolémées et les animaux sacrés", en: La gloire d'Alexandrie. Exposition. Paris Musée du Petit Palais, 7 mai - 26 juillet 1998 ,
Paris: 192-199.

Chauveau, M.; Thiers, Ch. Macédoniens", en: P. Briant y F. Joannès nide et les royaumes hellénistiques (vers 350 300 av. F.-C.). Actes du colloque organisé au Collège de France par la "Chaire d'histoire et civilisation du monde achéménide et de l'empire d'Alexandre » et le «Réseau interdes » (GDR 2538 CNRS), 22-23 novembre 2004 (Persika 9), Paris: 375-404

ClarysSe, W.

1985 "Greeks and Egyptians in the Ptolemaic Army and Administration", Aegyptus 65: 57 66.
2006 "L'Égypte en transition: des Perses aux national d'études et de recherches achéméni- 
1992 "Some Greeks in Egypt", en: J.H. Johnson (ed.): Life in a Multi-Cultural Society: yond (SAOC 51 ), Chicago: 51-56.

2000a The Ptolemies Visiting the Egyptian Chora", en: L. Mooren (ed.): Politics, $A d-$ ministration and Society in the Hellenistic and Roman World: Proceedings of the Inter national Colloquium, Bertinoro, $19-24$ fuly 1997 (Stud. Hellen. 36), Leuven: 29-53.

$2000 \mathrm{~b}$ "Ptolemées et temples", en: D. Valbelle y J. Leclant (eds.): Le décret de Memphis. Colloque de la Fondation Singer-Polignac a occasion de la celebranion du bicentenaire de la decouverte de la Pierro de Roselle. Paris. er juin 1999, Paris: 41-65

2007 "Toponymy of Fayyum Villages in the Davoli (eds): Nero Archaeological and Papyrological Researches on the Fayyum: Proceedinos of the International Meeting of $E$ orptolo cy and Papyrology, Lecce, June 8th-10th 2005 (PapLup 14), Galatina (Lecce): 67-81.

2010 "Egyptian Temples and Priests: GraecoRoman", en: A.B. Lloyd (ed.): A Compa nion to Ancient Egypt, Chichester: vol. 274-290.

Clarysse, W.; Thompson, D.J.

2006 Counting the People in Hellenistic Egypt. Cambridge Classical Studies). Cambridge, 2 vols.

Clarysse, W.; VAN DER VeKen, G.

1983 The Eponymous Priests of Ptolemaic Egypt: Chronological Lists of the Priests of Alexandria and Ptolemais with a Study of the Demotic Transcriptions of their Names (P. L. Bat. 24). Leiden.

Clarysse, W.; VAndorpe, K.

995 Zénon, un homme d'affaires grec à l'ombre des pyramides (Ancorae 14). Louvain.

998 The Ptolemaic Apomoira", en: H. Me laerts (ed.): Le culte du souverain dan 'Egypte ptolemaique au IIT siecle avan notre ère. Actes an collogue international, Bruxelles 10 mai 1995 (Stud. Hellen. 34) Leuven: 5-42.
Clayman, D.L.

ice II and the Golden Age of Ptolemaic Egypt (Women in Antiquity). Oxford.

Coussement, $\mathrm{S}$.

2016 'Because I am Greek': Polyonymy and the Expression of Ethnicity in Ptolemaic Egypt (Stud. Hellen. 55). Leuven.

CRAWFORD, D.J.

971 Kerkeosiris: An Egyptian Village in the Ptolemaic Period (Cambridge Classical Studies). Cambridge.

980 "Ptolemy, Ptah and Apis in Hellenistic Memphis", en: D.J. Crawford, J. Quac gemphis (Stud. Hellem.

Cruz-Uribe, E.

2010 "Social Structure and Daily Life: GraecoRoman", en: A.B. Lloyd (ed.): A Companion to Ancient Egypt, Chichester: vol. 1, 491-506.

Collins, A.

2014 'Alexander's Visit to Siwah: A New Analysis", Phoenix 68: 62-77

DAVoli, $\mathrm{P}$

998 L'archeologia urbana nel Fayyum di eta ellenistica e romana (Missione Congiunta delle Universita di Bologna e di Lecce in Egitto; "Sthenaeum, Monografie I). Napoli.

2010 "Settlements - Distribution, Structure, Aloyd (ed): A Companion to Ancient Eopt, Chichester: vol. 1, 350-369.

De Meulenaere, $\mathrm{H}$.

1991 "Le protocole royal de Philippe Arrhidée", CRIPEL 13: 53-58.

2003 "Autograph Confirmation in Demotic Private Contracts", $C d E$ 78: 66-111.

DEPUYDT, L.

2010 "New Date for the Second Persian ConEgypt: 340/39 B.C.E.", J EgH 3: 191-230.
DILLERY, J.

1999 "The First Egyptian Narrative History: Manetho and Greek Historiography", ZPE 127: 93-116.

2013 "Manetho", en: T. Whitmarsh y S. Thomson (eds.): The Romance between Greece and the East, Cambridge: $38-58$.

2015 Clio's Other Sons an Afterword on Demetrius. Ann Arbor.

Dunand, F.

1981 "Fête et propagande à Alexandrie sous les Lagides", en: F. Dunand (ed.): La Fete, pratique et discours. D'Alexandrie hellenistique a la Mission de Besangon (Annales Litheraires de 'Universite de Besan (A 262, Centrac ne 42), Paris: 13

ELDAMATY, M.M.

2011 "Die ptolemäische Königin als Weiblicher Horus", en: A. Jördens y J.F. Quack (eds.) Druck Die Zeit Ptolemaios' VI bis Vußserem ternationales Symposion Heidelberg 16.19. 9.2007 (Philippika 45), Wiesbaden: 24-57.

El-Masry, Y.; Altenmüller, H.; Thissen, H.-J. 2012 Das Synodaldekret von Alexandria aus Fahre 243 v.Chr. (BSAK 11). Hamburg.

ENGSHEDEN, $\AA$.

2016 "À l'écoute des voyelles dans les noms des souverains gréco-macédoniens en hiéto-

FALIVENE, M.R.

1991 "Government, Management, Literacy: As" Early Hellenistic Period", AncSoc 22: 203227.

2009 "Geography and Administration in Egyp (332 BCE-642 CE)", en: R.S. Bagnal (ed.): The Oxford Handbook of Papyrology, Oxford: $521-5$

FISCHER-BOvet, C.

2014 Army and Society in Ptolemaic Egypt (Armies of the Ancient World). Cambridge.
FRASER, P.M.

.

García Moreno, L.A.

992 "El Egipto indígena y la Monarquía Tolemaica", en: L.A. García Moreno y A. Pérez Largacha (eds.): De Narmer a Ciro (3150 a.C.-642 d.C.) (Aegyptiaca Complutensia 1), Alcalá de Henares: 115-120.

GaUthiER, $\mathrm{H}$

1916 Le livre des rois d'Égypte. Recueil de titres et protocoles royaux, noms propres de rois, reines, princes, princesses el parents derois, suivi d'un index alphabétique, vol. IV: De la XXVe dy nastie à la fin des Ptolémées (MIFAO 20). Le Caire.

GILL, J.C.R.

2015 "Beyond the Fayum: The Development of Egypt's Western Oases during the Ptolemaic Period", en: J. Cox, C.R. Hamilton, wart (eds.): Ancient Cultures at Mo D. Steversity: Proceedings of a Conference held be tween 18 -20 October 2013 on Approaches to Studying the Ancient Past (BAR-IS 2764$)$ Oxford: 79-85.

2016 Dakhleh Oasis and the Western Desert of Egypt under the Ptolemies (Dakhleh Oasis Project Monograph 17). Oxford.

Gómez Espelosín, F.J.

1992 "¿Reyes y dioses? La percepción de la monarquía en el Egipto helenístico", en: (eds.): De Narmer a Ciro (3150 a.C. -642 d.C.) (Aegyptiaca Complutensia 1), Alcalá de Henares: 131-143.

GORRe, G

2009 Les relations du clerge égyptien et des Lagides d'après les sources privées (Stud. Hellen. 45). Leuven.

GOUDRIAAN, K.

1988 Ethnicity in Ptolemaic Egypt (Dutch Monographs on Ancient History and Archaeology 5) 
GouËsSAN, A.

$\mathrm{HuB}, \mathrm{W}$

2013 "La đovфń ptolémaïque royale", $D H A 39 / 2$ 73-101.

GozzoLI, R.B

2006 The Writing of History in Ancient Egypt during the First Millennium BC (ca. 1070-180 BC): Trends and Perspectives (CHP EOptology Trends and. ptolemaiischen Äoypten (Historia, Einzelschriften 85$)$. Stuttgart.

1 Agypten in hellenistischer Zeit, 332-30 v. Chr. München.

HALLOF,

2010 Schreibungen der Pharaonennamen in den Ritualszenen der Tempel der griechisch-römischen Zeit Ägyptens, parte I: Die griechischen Könige (SRaT 4.1). Dettelbach.

HAZZARD, R.A.

000 Imagination of a Monarchy: Studies in Ptole maic Proparanda (Phoenix, Supplementary Volume 37). Toronto, London.

HeINEN, $\mathrm{H}$

1978 "Aspects et problèmes de la monarchie ptolémaïque", Ktèma 3: 177-199.

HÖLBL, G.

992 "Königliche Legitimität und historische Umstände im Spiegel der pharaonischen Titulaturen der griechisch-römischen Zeit - Einige Interpretationen und Diskus sionsvorschläge , en: Sesto Congresso Internazionale di Egittologia, Atti, Torino: vol. $273^{-27} 8$.

2001 A History of the Ptolemaic Empire. London (ed. orig. Darmstadt: 1994)

2003 "Ptolemaische Königin und weibliche Pharao", en: N. Bonacasa, A.M. Donado ni Roveri, S. Aiosa y P. Minà (eds.): Farao-
ni come dei - Tolemei come faraoni. Atti del $\mathrm{V}$ Congresso internazionale Italo-Egiziano, Torino, Archivio di Stato, 8-12 dicembre 2001, $\mathrm{Pa}$ lermo: 88-97.

Hornbostel, W.

973 Sarapis. Studien zur Überlieferungsgeschichte, den Erscheinungsformen und Wandlungen der Gestalt eines Gottes (EPRO 32). Leiden.

De Sacerdotibus Sacerdotisque Alexandri Magni et Lagidarum Eponymis (Verhandelingen België, Klasse der Letteren 42). Brussel.
(2)

JOHNSON, J.H. Ptolemaic Egypt", en: L.H. Lesko (ed.): Egyptological Studies in Honor of Richard A. Birthday December 10, 1983, Hanover: 7084 .

KAMAL, A.B.

1904-1905 Steles ptolémaĩques et romaines (Catalogue général des antiquités égyptiennes du Musée du
Caire nos 22001-22208). Le Caire, 2 vols.

Katary, S. maic Period), en: J.C. Moreno García W. Wendrich (eds.): UCLA Encyclopedia of Egyptology, Los Angeles: 1-35. [https:// escholarship.org/uc/item/1nrid3s9 http://digital2.library.ucla.edu/viewItem. do?ark=21198/zzoo2bfks5]

KeEnan, J.G.; Manning, J.G.; Yiftach-Firanko, U. (EDS.)

2014 Law and Legal Practice in Egypt from Alexan der to the Arab Conquest: A Selection of Papytions and Commentary. Cambridge.

Kehoe, D.

"The Economy: Graeco-Roman", en: A.B. Lloyd (ed.): A Companion to Ancient Egyp Chichester: vol. 1, 309-325. chen Priester. Studien zur Geschichte des

Koenen, L.

1986 "The Role of the Egyptian Priesthood in

2012 "Land Tenure (to the End of the Ptolerological Sources in Translation with Introdu-
1983 "Die Adaptation ägyptischer Königsideologie am Ptolemäerhof", en: E. van't Dack, P. van Dessel y W. van Gucht (eds.): Egypt and the Hellenistic World: Proceedings of the International Colloquium, Leuven - 24-26 May 1982 (Stud. Hellen. 27), Lovanii: 143-19o.

1993 "The Ptolemaic King as a Religious Figure", en: A. Bulloch, E.S. Gruen, A.A Long y A. Stewart (eds.): Images and Ideologies: Self-definition in the Hellenistic World (Hellenistic Culture and Society 12), Berkeley: $25^{-115}$.

KURTH, D.

1981 "Alexander the Great at Siwah", $A n c W 4$ $109-127$

GER, M.-T.

1980 Corpus des Ordonnances des Ptolémées (C. Ord. Ptol.) (Académie Royale de Belgique, Mémoires de la Classe des Letres, Collecilon in-8, ${ }^{2}$ serrie 64.2). Bruxelles (2a ed. rev. y aum.).

Ord. Ptol*). Bilan des additions at coées (C. (1964-1988). Compléments à la bibliographie (Papyrologica Bruxellensia 24; Documenta et Opuscula 11). Bruxelles.

"Aner makedonischen und ptolemäischen Könige", en: $L A$

LA'DA, C.A.

994 "Ethnicity, Occupation and Tax-Status in "Ptolemaic Egypt", en: Acta Demotica: Acts Pisa, th-8th September 1993 ( = EVO 17 ), Pis. 183-189.

2002 Foreign Ethnics in Hellenistic Egypt (Stud. Hellen. 38; Prosopographia Ptolemaica 10). Leuven.

LADYNIN, I.A.

2014 "The Argeadai Building Program in Egypt in the Framework of Dynasties' XXIXXXX Temple Building", en: V. Grieb, K. Nawotka y A. Wojciechowska (eds.) Alexander the Great and Egypt: History, Art, Tradition. Wroctaw/Breslau 18./19. Nov. 2011 (Philippika 74), Wiesbaden: 221-240.

LANCIERS, E.

1991 "Die agyptischen Priester des ptole-

1993 "Die Opfer im hellenistische Herrscherkult und ihre Rezeption bei der einheimischen Bevölkerung der hellenistischen Reiche" en: J. Quaegebeur (ed.): Ritual and Sacrifice in the Ancient Near East: Proceedings of the In ternational Conference organized by the Katho20th of April 19g1 (OLA 55), Leuven: 203-223.
1997 "Cléomène de Naucratis", $B C H$ 121: 71-93. 2003 Alexandre le Grand. Monnaie, finances et po
tique. Paris.

LEwIS, N.

Greeks in Ptolemaic Egypt: Case Studies in the Social History of the Hellenistic World. Oxford.

LIPPERT, S.L.

8 Einfürung in die altägyptische Rechtsgeschichte (Einfuhrung . Berlin. UCLA Encyclopedia. Wendrich (eds.): UCLA Encyclopedia of Egyptology, Los uc/item/omr 4 h4fv / / http//dipitals library.ucla.edu/viewItem.do?ark=21198/ zzoo2bzzgj]

2012b "Law Courts", en: E. Frood y W. Wendrich (eds.): UCLA Encyclopedia of Egyptology, Los Angeles: 1-26. [https://escholarship. org/uc/item/4136j3s7 / http://digital2.
library.ucla.edu/viewItem.do?ark=21198 zzoo2djg21]

2017 "La codification des lois en Égypte à l'époque perse", en: D. Jaillard y Ch. NiL'écriture du droit dans l'Antiquité (BZAR 19), Wiesbaden: $78-98$.

LLOYD, A.B

2000 "The Ptolemaic Period (332-30 BC)", en 1. Shaw (ed.): The Oxford History of Ancien Egypt, Oxford: $395-421$. 
2002 "The Egyptian Elite in the Early Ptolemaic Merkelbach, R. D. Ogden (ed.): The Hellenistic World: Nere Perspectives, Swansea: 117-136.

Manning, J.G.

999 "The Land-Tenure Regime in Ptolemaic pper Egypt", en: A.K. Bowman y E. Rogan Modern Times (PBA 96), Oxford: 83-105

ga "Demotic Law", en: R. Westbrook (ed.): A History of Ancient Near Eastern Law (Handbook of Oriental Studies, Section One: The Near and Middle East 72), Leiden: vol. 2, 819-862.

2003 b "Edfu as a Central Place in Ptolemaic History", en: K. Vandorpe y W. Clarysse (eds.): Edfu, an Egyptian Provincial Capital in the Ptolemaic Period: Brussels, 3 September 2001, Brussel: 61-73.

2003c Land and Power in Ptolemaic Egypt: The Structure of Land Tenure. Cambridg.

2007 "Hellenistic Eoypt", en: W. Scheidel Morris y R. Saller (eds.): The Cambridge Economic History of the Greco-Roman World, Cambridge: $434-459$

2010 The Last Pharaohs: Egypt under the Ptolemies, 305-30 BC. Princeton.

McGing, B.C.

997 "Revolt Egyptian Style. Internal Opposition to Ptolemaic Rule", AfP 43: 273-314.

McKenzie, J.

The Architecture of Alexandria and Egypt, c. 300 $B C$ to $A D 700$. New Haven.

MÉLÈze]-ModrzeJewsKi,

975 "Chrématistes et laocrites", en: J. Bingen , Cambier y G. Nachtergael (eds.): Le monde grec. Penséé, littérature, histoire, documents. Bruxelles, Faculté de Philosophie et Lettres 52 , Bruxelles: 699-708.

1995 "Law and Justice in Ptolemaic Egypt", en M.J. Geller, H. Maehler y A.D.E. Lewi (eds.): Legal Documents of the Hellenistic
World: Papers from a Seminar Arranged by the Institute of Classical Studies, the Institute of Jero ish Studies and the Warburg Institute, University of London, February to May 1986, London: 1-19 tische Religion nach den Quellen dargestellt. München $\left(2^{\mathrm{a}}\right.$ ed. rev.

Minas, M.

998 "Die xavnфooos. Aspekte des ptolemaischen Dynastiekults", en: H. Melaerts (ed.) Le culte du souverain dans l'Égypte ptolémarque au Irr siede avant norre ero. Actes du collo-

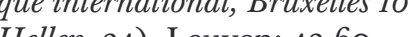

005 "Macht und Ohnmacht. Die Repräsentation ptolemäischer Königinnen in ägyptischen Tempeln", AfP $51:$ 127-154

MOOREN, L

33 "The Nature of the Hellenistic Monarchy", en: E. van't Dack, P. van Dessel y W. van Gucht (eds.): Egypt and the Hellenistic World: Proceedings of the International Colloquium, Lovanii: $205-240$.

MuelLer, $\mathrm{K}$

2006 Settlements of the Ptolemies: City Foundations and Nere Settlement in the Hellenistic World (Stud. Hellen. 43). Leuven.

OrRieux, $\mathrm{C}$

983 Les papyrus de Zénon. L'horizon d'un grec en 7.C. Paris.

985 Zénon de Caunos, parépidèmos, et le destin sancon 320; Centre de Recherches d'Histoire Ancienne 64). Paris.

987 "Les Lagides, les élites indigènes et la monarchie bicéphale", en: E. Lévy (ed): Le système palatial en Orient, en Grèce et à Rome. Actes du Colloque de Strasbourg, 19-22 juin 1985 (Universite des Sciences Humaines de Stras bourg, Travaux du Centre de recherche sur . 327-343

Pestman, PI.

$981 \quad$ A Guide to the Zenon Archive. (P. L. Bat. 21). Leiden, 2 vols.
1985 "Registration of Demotic Contracts in Egypt. P. Par. 65; 2nd cent. B.C.", en: J.A Ankum, J.E. Spruit y F.B.J. Wubbe (eds.) Satura Roberto Feenstra sexagesimum quintum annum aetatis complenti ab alumnis collegis amicis oblata, Fribourg: 17-25

1995 "Haronnophris and Chaonnophris: Two Indigenous Pharaohs in Ptolemaic Egyp (205-186 B.C.)", en: S.P. Vleeming (ed.) Hundred-Gated Thebes: Acts of a Colloquium on Thebes and the Theban Area in the Graeco-Roman Period (P. L. Bat. 27), Leiden: 101-137.

PFeIfFer, S.

2008a Herrscher- und Dynastiekulte im Ptolemäer reich. Systematik und Einordnung der Kultformen (MBPAR 98). München.

2008b" The God Serapis, His Cult and the Beginnings of the Ruler Cult in Ptolemaic Egypt", en: P. McKechnie y P. Guillame (eds.): Ptolemy II Philadelphus and His World (Mnemosyne, Supplement 300), Leiden: 387 408.

2015 Griechische und lateinische Inschriften zum Ptolemäerreich und zur römischen Provin Aegyptus (Einführungen und Quellentexte zur Ägyptologie 9). Berlin.

2016 "The Ptolemies: Hellenistic Kingship in Egypt", en: Oxford Handbooks Online, Oxford: 1-31. Thttp://www.oxfordhandbooks. com (DOI: 10.1093/oxfordhb/9780199935390.013.23)]

Plaumann, G.

10 Ptolemais in Oberägypten. Ein Beitrag zur Geschichte des Hellenismus in Agypten (Leipziger historische Abhandlungen 18). Leipzig.

Pollard, N

2010 "Military Institutions and Warfare: GraecoRoman", en: A.B. Lloyd (ed.): A Companion to Ancient Egypt, Chichester: vol. 1, 446-465.

Préaux, C.

939 L'Economie royale des Lagides. Bruxelles.

965 "Polybe et Ptolémée Philopator", $C d E 4_{4}^{\circ}$ 364-375.
QUAEGEBEUR, J.

"Documents égyptiens et rôle économique "Doce en Eypte hellénistique", en:

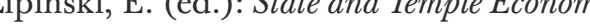
in the Ancient Near East: Proceedings of the Inlieke Unizersiteit Leuzen from by the Kathoitth of April $1978(O L 46)$, Lew 14th of April 1978 (OLA 6), Leuven: vol. 2 Priest Family in the Hellenistic Period rysse, Studies on Ptolemaic Memphis (Stud. Hellen. 24), Lovanii: $43-81$.

1998 "Documents encyptiens anciens et nouveaux relatifs à Arsinoé Philadelphe", en H. Melaerts (ed.): Le culte du souverain dans l'Egypte ptolémaique au III siècle avant notre ère. Actes du colloque international, Bruxelles 10 mai 1995 (Stud. Hellen. 34), Leuven: 73

REYMoND, E.A.E.

1981 From the Records of a Priestly Family from Memphis, vol. I ( $\ddot{A} A 38)$. Wiesbaden.

Rice, E.E.

1983 The Grand Procession of Ptolemy Philadelphus (Oxford Classical and Philosophical Monographs). Oxford.

ROLLER, D.W.

2010 Cleopatra: A Biography (Women in Antiquity). Oxford.

RostovtZeFF, M.I.

Th1 The Social \& Economic History of the Hellenis tic World. Oxford, 3 vols.

ROWLANDSON, J.

2003 "Town and Country in Ptolemaic Egypt" en. A. Erskine (ed.): A Companion to the Hellenistic World, Oxford: 249-263.

2010 "Administration and Law: Graeco-Roman" en: A.B. Lloyd (ed.): A Companion to Ancien Egypt, Chichester: vol. 1, 237-254.

SALES, J.D.C.

05 Ideologia e propaganda real no Egipto ptolomaico (305-30 a.C.). Lisboa. 
SAMUEL, A.E.

1993 "The Ptolemies and the Ideology of Kingship", en: P. Green (ed.): Hellenistic History Delia, "Response" y "Discussion").

SCHÄFER, D

2011 Makedonische Pharaonen und hieroglyphische Stelen. Historische Untersuchungen zur Satrapenstele und verwandten Denkmälern (Stud. Hellen. 50). Leuven.

SEIDL, E.

1962 PtolemäischeRechtsgeschichte ( $\ddot{F} F$ 22). Glück$\operatorname{stadt}\left(2^{a}\right.$ ed. rev. y aum.).

Stambaugh, J.E.

1972 Serapis under the Early Ptolemies (EPRO 25)

TAKÁCS, S.A.

995 Isis and Sarapis in the Roman World (Re ligions in the Graeco-Roman World 124).

Thiers, C.

2009 "Observations sur le financement des l'époque ptolémaïque", en: R. Preys (ed): 7 Äoyptologische Tempeltagung: Structuring Religion. Leuven, 28. September - 1. Oktober 2005 (Köniotum Staat und Gesellschaft früher Hochkulturen 3.2), Wiesbaden: 231-244.

Thompson, D.J.

1990 "The High Priests of Memphis under Ptolemaic Rule", en: M. Beard y J. North
(eds.): Pagan Priests: Religion and Power in the Ancient World, London: 95-116.

1992a "Literacy and the Administration in Early "Ptolemaic Egypt", en: J.H. Johnson (ed.) Life in a Multi-Cultural Society: Egypt from Cambyses to Constantine and Beyond (SAOC 51), Chicago: 323-326.

1992b "Language and Literacy in Early Hellenis tic Egypt", en: P. Bilde, T. Engberg-Pedersen, L. Hannestad y J. Zahle (eds.): Ethni-
city in Hellenistic Egypt (Studies in Hellenistic Civilization 3), Aarhus: 39-52.
1994 "Literacy and Power in Ptolemaic Egypt", en: A.K. Bowman y G. Woolf (eds.): Literacy
and Power in the Ancient World, Cambridge: $67-83$

1997 "The Infrastructure of Splendour: Census and Taxes in Ptolemaic Egypt", en: P. Cartledge, P. Garnsey y E. Gruen (eds.): . Society 26), Berkeley:

999a "Irrigation and Drainage in the Early Ptolemaic Fayyum", en: A.K. Bowman y E. Ronic to Modern Times (PBA 96), Oxford: 107122.

1999b "New and Old in the Ptolemaic Fayyum", en: A.K. Bowman y E. Rogan (eds.): Agriculture in Egypt: From Pharaonic to Moder "Phildelphes' Proc

000 "intic Power (ed.): Politics, Administration and Society in the Hellenistic and Roman World: Proceedings of the International Colloquium, Bertinoro, 19 24 July 1997 (Stud. Hellen. 36), Leuven: 365 388.

2001 "Hellenistic Hellenes: The Case of Ptole maic Egypt", en: I. Malkin (ed.): Ancient Perceptions of Greek Eihnicity (Center : An Helle-

2008 "Economic Reforms in the Mid-Reign of Ptolemy Philadelphus", en: P. McKechnie and His World (Mnemosyne, Supplement 300), Leiden: 27-38.

2009 "The Multilingual Environment of Persian and Ptolemaic Egypt: Egyptian, Aramaic, and Greek Documentation , en: R.S. BagOxford: $395-417$.

the Ptolemies. Princeton $(2$

UEBeL, $\mathrm{F}$.

1968 Die Kleruchen Ägrptens unter den ersten sechs Ptolemäern (ADAW 3). Berlin.

VANDORPe, $\mathrm{K}$.

2010: "The Ptolemaic Period", en: A.B. Lloyd (ed.): A Companion to Ancient Egypt, Chichester: vol. 1, 159-179.
VAndorpe, K.; Clarysse, W.

2008 "Egyptian Bankers and Bank Receipts in "Eelenistic and Early Roman Egypt", en K. Verboven, K. Vandorpe y V. Chankowsk (eds.): Pistoi dia tèn technèn. Bankers, Loans and Archives in the Ancient World. Studies in Honour of Raymond Bogaert (Stud. Hellen. 44), Leuven: 153-168.

VAN'T DACK, E

1989 "Toujours le testament d'un Ptolémée Alexandre , en: E. van t t Dack, W. Clarysse, The Fudean-Syrian-Esytian Conflict of 109 101 B.C.: A Multilingual Dossier Concerning "War of Scepters" (Collectanea Hellenistica 1 ) Brussel: 150-161.

VEÏSSE, A.-E.

2004 Les « révoltes égyptiennes». Recherches sur les troubles intérieurs en Égypte du règne de Ptolé41). Leuven.

2009 "L' «ennemi des dieux » Harsièsis", en: A Jördens y J.F. Quack (eds.): Ägypten zwoischen innerem zwist und äußerem Druck. Di zeit Ptolemaios 1 . bis VIII. Internationalippika 45), Wiesbaden: 92-102.

\section{VERHOOGT, A.M.F.W.}

1998 Menches, Komogrammateus of Kerkeosiris: The Doings and Dealings of a Village Scribe in the
Late Ptolemaic Period (120-110 B.C.) (P. L. Bat. 29). Leiden.

2005 Regaling Officials in Ptolemaic Egypt: A
Dramatic Reading of Official Accounts from the Menches Papers (P. L. Bat. 32). Leiden.

VIDMAN, L.

1970 Isis und Sarapis bei den Griechen und Römern Epigraphische Studien zur Verbreitung und zu den Tragern des ägyptischen Kultes (Religionsgeschichtliche Versuche und Vorarbeiten 29). Berlin.

VierRos, M

2012 Bilingual Notaries in Hellenistic Egypt: A Study of Greek as a Second Language (Collecta-
nea Hellenistica 5). Brussels.
VON BECKERATH, J

Handbuch der agryptischen Königsnamen (MAS 49). Mainz am Rhein ( $2^{\mathrm{a}}$ ed. rev.

VON REDEN, S

2007 Money in Ptolemaic Egypt: From the Macedonian Conquest to the End of the Third Century $B C$. Cambridge

WinNICKI, J.K.

1994 "Carrying off and Bringing Home the Sta cues of the Gods. On an Aspect of the Re-

WoLfF, H.J.

1970 Das fustizwesen der Ptolemäer (MBPAR 44). München ( $2^{a}$ ed revi)

1978 Das Recht der oriechischen Papyri Äryptens in der Zeit der Ptolemaeer und des Prinzipats, vol. II: Organisation und Kontrolle des privaten Rechtsverkehrs (Handbuch der Altertums wissenschaft 10.5.2). München.

2002 Das Recht der griechischen Papyri Agyptens in der Zeit der Ptolemaeer und des Prinzipats, vol. I: Bedingungen und Triebkräfte des Rechtsentwicklung (ed. H.A. Rupprech) (Handbuch der Altertumswissenschaft 10.5.1). München.

Yiftach-Firanko, U.

2009 "Law in Graeco-Roman Egypt: Hellenization, Fusion, Romanization", en: R.S. Baglogy, Oxford: $541-560$. 


\section{Et il pleut sur Bruxelles}

Cristina GIL PANEQUE

Siempre me pregunté por qué un día decidieron quitar el busto de Nefertiti. lectura de la biblioteca de la repsociation Égyptologique Reine Élisabeth ${ }^{1}$. Colocada estratégicamente sobre unos ficheros de madera, de esos antiguos con múltiples cajones, daba buena cuenta de la labor de los investigadores itinerantes. La biblioteca en sí rezuma un encanto especial. Se encuentra dentro del Musée du Cinquantenaire, en uno de los parques más emblemáticos de Bruselas. Para acceder a ella se han de atravesar diversas salas del museo, excusa para Atravesada la puerta una tranquilidad abrumadora aco a visitante haciéndole sentir como si el paso del tiemo se remo si el paso del tiova. Le gustaba venir para evadirse y escapar de la rutina.
sus inseparables Adoratrices del Dios y encontrar la inspiración. Las sutiles notas de vainilla y almendra que dicen desprenden los libros viejos. El perfume inconfundible de la pipa del y almendra que dicen desprenden los libros viejos. El perfume inconfundible de la pipa del
Profesor, su querido mentor Herman De Meulenaere ${ }^{2}$. La pausa del mediodía con olor a té. El silencio... Ni siquiera el fondo gris tras los ventanales consigue romper esa magia. ¡Bendito clima bruselense! O lo amas o lo detestas. Cova estaba entre los primeros. Tenía un vínculo especial que le unía a esta ciudad desde su etapa como estudiante. Debe de ser verdad lo que se dice sobre esta parte del Norte de Europa: que se llora dos veces, una cuando llegas y otra cuando te vas.

Cova llevaba Egipto en el corazón. Los ecos de sus clases en los pasillos de la facultad de Filosofía y Letras de la Universidad Autónoma de Madrid son la prueba de lo que conseguía trasladar y contagiar a sus alumnos. Sentirse querido como profesor es probablemente el mayor triunfo para quien decide dedicarse a transmitir el saber en cuerpo y alma. Compartir con ella mis años de doctorado ha sido todo un honor. Bajo su tutela comenzó una fantástica aventura que me ha llevado a donde estoy hoy. El escritor Xavier de Maistre 3 decía que los recuerdos de la felicidad pasada son las arrugas del alma. Muchos son los que se forjaron al lado de Cova. Fueron años de juventud, de ganas de aprender y de ganas de enseñar. Mucha ilusión por Fueron años de juventud, de ganas de aprender y de ganas de enseñar. Mucha ilusión por
crecer, por crear proyectos y un orgullo especial de ser parte de ellos. Cova tenía un alma de crecer, por crear proyectos y un orgullo especial de ser parte de ellos. Cova tenía un alma de
luchadora y una pasión testaruda hacia la disciplina que embarcaba a quienes la escuchaban. Su franqueza, su cariño y su confianza pronto supieron traspasar las barreras académicas y continuaron mucho más allá de mi puesta de largo como egiptóloga.

Han sido tantas las anécdotas y vivencias que forman parte de esa maleta con la que uno viaja toda la vida... Esa en la que solo tienen cabida unos pocos objetos tras la selección natural

La Association Égyptologique Reine Élisabeth, antigua Fondation Égyptologique Reine Élisabeth, fue fundada por Jean Capart en 1923. Tiene su sede en el Musée du Cinquantenaire (Musées Royaux d

2 H. De Meulenaere (1923-2011) fue director de la Association Égyptologique Reine Élisabeth desde 1975.

3 Expédition nocturne autour de ma chambre, Xavier de Maistre, 1825. 
del paso del tiempo. En el reducto de su despacho o en la animada cafetería, improvisado confesionario, no vimos pasar los años. Largas charlas en las que se aunaron alegrías, nervios, lloros... y muchas risas. Porque Cova hacía alarde de un gran sentido del humor. El mismo que hacía que, en lugar de decantarse por la triunfal Aida, prefiriese La Corte del Faraón, más hilarante, más modesta, más suya. Ese lado pizpireto que le vi, sentada en la alfombra del salón y jugando con mis hijos, durante su última escapada a Bruselas. De no ser porque eran muy pequeños seguro que se hubiesen reído del chiste del cocodrilo.

pequeños seguro que se hubiesen reído del chiste del cocodrilo.
Desde la ciudad en la que fue tan feliz y con una con-emoción contenida, mi más sincero Desde
recuerdo.

\section{Cristina Gil}




\section{Índice | Contents}

Trabajos de Egiptología está producida por

de la Universidad de La Laguna

$\mathrm{C} /$ Blanco $1,2^{\circ}$

38400 Puerto de la Cruz

España

( De los textos: sus autores y Trabajos de Egiptología

Diseño de arte y maquetación

Amparo Errandonea

Imprime: Gráfica Los Majuelos

Depósito Legal: TF 935-2015
José Miguel BARRIOS MUFREGE Covadonga en la Caldera del Teide 5

Foreword

Carta a una hermana en la luz / Letter to an enlightened sister 11

Estudio preliminar de la cerámica procedente de las excavaciones en la $\Pi \pi$ 209, Luxor,

Egipto

ZUlema BARAHONA MENDIETA

Amparo ERRANDONEA Liebestod 31

La ocupación macedónica y la Dinastía Lágida. Impacto político, económico y social Francisco BOSCH PUCHE

$$
\text { Cristina GIL PANEQUE Et il pleut sur Bruxelles } 75
$$

Reflexiones sobre Meretseguer en la estela EA272 del British Museum

Elisa CASTEL RONDA

Fernando GUERRA-LIBRERO FERNÁNDEZ Taftich 93

Ramesses III as Guarantor of Maat: the Iconographic Evidence at Medinet Habu Salvador COSTA, Teresa MAGADÁN

Fernando GUERRA-LIBRERO FERNÁNDEZ Muro de la casa de excavación 115

Iconographic Rendering of the Notion of Purification in Two Elements Included in the Vignettes of Chapters 17 and 125 of the Book of the Dead

ucía DÍAZ-IGLESIAS LLANOS

$$
\text { Isabel SÁNCHEZ MARQUÉS Adoratriz del Dios } 163
$$

Taboo - bwt?

Paul John FRANDSEN

Fernando GUERRA-LIBRERO FERNÁNDEZ Barco en el Nilo 193

Flat-Section Hairpins during the Egyptian Predynastic Period? A Proposa

$$
\text { of Identification and Typology }
$$

Candelaria MARTÍN DEL RÍO ÁLVAREZ

Isabel SÁNCHEZ MARQUÉS Plañidera 211 
José Miguel BARRIOS MUFREGE Covandonga en el patio de la TT 209, excavando el depósito de momificación 243

\section{The Courtyard of TT 209 (Areas C1 and C2). Seasons 2012 to 2014}

Miguel Ángel MOLINERO POLO, Cristo Manuel HERNÁNDEZ GÓMEZ

Hassan MOHAMED ALI, Saad BAKHIT ABD EL HAFEZ

Daniel Miguel MÉNDEZ RODRíGUEZ, Fernando GUERRA-LIBRERO FERNÁNDEZ,

Carlos GARCÍA ÁVILA, Lucía DíAZ-IGLESIAS LLANOS,

Zulema BARAHONA MENDIETA, José Miguel BARRIOS MUFREGE,

Paloma COLL TABANERA

Isabel SÁNCHEZ MARQUÉS Papiros 271

Algunas reflexiones sobre Uluburun y el intercambio comercial y cultural

en el Mediterráneo Oriental

Antonio PÉREZ LARGACHA

Fernando GUERRA-LIBRERO FERNÁNDEZ Hotel Sheherazade 289

The Framework of the Meeting. Narrative Uses of Stelae in Egyptian Literary Texts José Ramón PÉREZ-ACCINO

Sacha GÓMEZ MOÑIVAS En recuerdo de Covadonga 301

\section{Introducción a la investigación arqueológica para estudiantes}

a través de reconstrucciones virtuales

Sofía PÉREZ-RUIZ, Ainara ACEBO, Pilar RODRÍGUEZ MARÍN, Sacha GÓMEZ MOÑIVAS

Isabel SÁNCHEZ MARQUÉS Out of the blue 311

Lucernas decoradas con la imagen de una rana del yacimiento de Oxirrinco,

El-Bahnasa, Egipto

Esther PONS MELLADO

Submission guidelines
245

A Covadonga le gustaba conducir, le apasionaba estar al volante de su coche. "Pareces una chica A del futurismo italiano", le decía un amigo, aunque su primer automóvil fuera pequeño, blanco con un techo amarillo y a veces le costase llegar a su destino. Estuvimos años riendo cuando nos acordábamos del nombre con que habíamos bautizado aquella máquina. En nuestro recuerdo, ella sigue siendo la joven radiante y activa que conocimos a sus veinte años. Y su personalidad permanece entre nosotros como un perfume indeleble, retomando los versos del poeta alejandrino que tanto le gustaba. Quienes asistieron a sus conferencias conocieron la calidez de su voz; sus clases en la universidad crearon vocaciones; son, sin embargo, los que compartieron con ella su amistad quienes disfrutaron de los rasgos más sobresalientes de su personalidad: la generosidad, la entrega desinteresada a los demás. Cova tenía una capacidad excepcional para la empatía hacia los que se le acercaban. Fso le hizo ganar afectos en todos los ámbitos de su vida y conservarlos, desde los compros des tributo proser. Este y la huella que dejó en su generación.

Un grupo de amigos que vivimos con ella sus labores de docencia, investigación o proyectos arqueológicos, decidimos rendirle un homenaje particular, uno más entre los que se le han dedicado desde el momento en que su $k a$ voló al cielo. Este volumen es el resultado de esa voluntad de crear nuestro monumento a su memoria, por tantas experiencias inolvidables compartidas. El homenaje ha querido ser un caleidoscopio de miradas desde las que reflejar la personalidad de Covadonga y hemos preferido romper el formato académico tradicional. Los artículos se entrelazan con fotografías, dibujos, semblanzas o poemas que pretenden dejar constancia de la huella que ella legó a sus autores. Es nuestra ofrenda para que su $b a$ siga regresando desde donde esté hasta nosotros, cada vez que la nombremos y en cada ocasión en que su recuerdo tome forma en nuestro corazón. 


\section{Foreword}

Covadonga enjoyed driving; she loved being behind the wheel of her car. A Uriend used to tell her "you look like a woman of the Italian Futurism," although her first car was small and white with a yellow roof, and sometimes had difficulties reaching its destination. We laughed for years remembering the name with which we baptized that machine. In our memories, she is still the radiant and active young woman we met in her twenties, and her personality remains among us as an indelible scent, to draw upon the verse of an Alexandrian poet that she loved so much. Those who attended her lectures knew the warmth of her voice, her classes at the university created vocations, however, it is those who shared her friendship who enjoyed the most outstanding features of her personality: generosity, and selfless dedication to others. Cova had an exceptional capacity for empathy toward those who approached her This allowed her to win affection in all aspects of herfe and to retain it, from the classmates of her early schooldays, to the a circles of all a the generations as the legacy of an exceptional individual, and the mark she left on her generation.

As a group of friends who lived with her through teaching, research, or archaeological projects, we have decided to pay her a particular tribute; one more among the many that have been dedicated to her from the moment her ka flew to heaven. This volume is the result of our desire to create for her a monument to so many unforgettable shared experiences. We decided that this tribute should be a kaleidoscope, to reflect Covadonga's personality, and we have thus preferred to break from the traditional academic format. The articles are intertwined with photographs, drawings, sketches, or poems that are intended to record the traces she left with their authors. It is our offering so that her ba keeps coming back to us from where she now is, every time that her memory takes shape in our hearts.

\section{Carta a una hermana en la luz} SON le habla a su padre, como la hija que le habla a su madre.

¡O Senet, Senet Meret! Que Osiris-Khentamentiu te otorgue millones de años respirando aliento en tu nariz, dándote pan y cerveza junto a Hathor, Señora de la Tierra de Luz.

Tu condición es como la vida millones de veces, por orden de los dioses que están en el cielo y la en tierra. Que Ha, Señor de Occidente, actúe en tu favor de acuerdo a sus deseos, que Anubis, Señor del Buen Entierro actúe para ti como él lo quiera. Que pueda levantar una barrera contra los enemigos, hombres y mujeres malvados que se oponen a tu casa, tus hermanos, tus padres, tu memoria y tus hombres
obras.

Fuiste excelente en la tierra, por lo que también serás capaz y eficiente en el Más Allá. Que se te hagan ofrendas, que se realice la fiesta Haker para ti, que hagan la fiesta del Wag, que te den pan y cerveza del altar de Khentamentiu. Que puedas viajar río abajo en la Barca del Ocaso y que navegues río arriba en la Barca de la Mañana. Que estés justificada junto a cada dios. Que te conviertas en río arriba en la Barca de la Mañana. Que estés justificada junto a
alguien elogiado por nuestros espíritus masculinos y femeninos.

¿Has visto estos lamentos ahora que estás allí en el Más Allá?

Oh, gran dolor! Útil es una queja para hablar de lo que se hace contra nosotros de una manera tan injusta. Aunque no hay nada que hayamos hecho contra los dioses, y aunque no hemos comido de sus ofrendas, jsin embargo nos han privado de ti

Te han traído aquí a la Ciudad de la Eternidad, sin que albergues ira contra nosotros. Pero si hubiera un reproche en tu corazón, olvídalo por el bien de tus hermanas y hermanos. Sé misericordiosa, sé misericordiosa, y así todos los dioses del nomo de This serán misericordiosos contigo.

Mantén alejadas todas las aflicciones dirigidas a nosotros, tus hermanas y hermanos, porque tú sabes que tenemos una gran necesidad de esto. Que vivas para nosotros y así el Grande te elogie. Que la cara del gran dios sea gozosa para ti, y que él te dé pan puro con ambas manos.

Todos los sacrificios funerarios se han realizado para la que está en la luz, a fin de que pueda interceder por nosotros, los sobrevivientes en la tierra que han quedado atrás. Por lo tanto, busca que el que causó aquello de lo que estamos sufriendo ahora te dé una explicación, porque necesitamos entender y queremos también ser justificados delante de los dioses como lo eres ahora, entendiendo todo, justificada y transfigurada.

Son los hermanos y hermanas quienes le hablan a su hermana, para quien la luz ya nunca se oscurecerá. 


\section{Letter to an enlightened sister}

is the brothers and sisters who are speaking to their sister like the son who is speaking to
his father, like the daughter who is speaking to her mother.

O Senet, Senet Meret! May Osiris-Khentamentiu make millions of years for you by breathing breath into your nose, by giving bread and beer beside Hathor, Lady of the Land-of-Light.

Your condition is like life millions of time, by command of the gods who are in heaven and earth May $\mathrm{Ha}$, Lord of the West, act on your behalf as he wishes, may Anubis, Lord of the Good Burial act for you as he wishes. May you erect a barrier against male and female enemies, male and female evil ones who oppose your house, your brother, your mother, your memory, your deeds.

You are one who was excellent on earth, therefore you will also be capable in the hereafter. May one make offerings to you, may one make the Haker-feast for you, may one make the Wag-feast for you, may one give you bread and beer from the altar of Khentamentiu. You will travel downstream in the Bark-of-the-Evening and sail upstream in the Bark-of-the-Morning. May you be given justification at the side of every god. Make yourself into someone praised by our male and female ghosts.

Have you seen this lamentation now that you are there in the hereafter?

$\mathrm{O}$, great grief! Useful is a complaint to speaking concerning this which is done against us in such an unjust way, although there is nothing that we have done against the gods, and although we have not eaten of his offerings, nevertheless they have deprived us of you!

You have been brought here to the City of Eternity, without you harbouring anger against us. But if there is a reproach in your heart, forget it for the sake of your sisters and brothers. Be merciful, be merciful, then all the gods of the Thinite nome will be merciful towards you.

Keep away all afflictions directed at us, your sisters and brothers, for you know we have a need for this. May you live for us in order for the Great One to praise you. May the face of the great god be joyous because of you, so that he will give you pure bread with both his hands.

All mortuary sacrifices are made for the enlightened one in order to intercede on behalf of the inhabitants of earth. Therefore seek an explanation from him who caused that of which we are suffering now, for we want to be justified in front of the gods same as you are now.

It is the brothers and sisters who are speaking to their sister, she for whom the light will never darken. 